\title{
Synthesis and Characterization of Hydroxyapatite- (HAP-) Clay Composites and Adsorption Studies on Methylene Blue for Water Treatment
}

\author{
Ebenezer Annan (D), ${ }^{1}$ Grace Karikari Arkorful, ${ }^{1}$ David Sasu Konadu ${ }^{D},{ }^{1}$ Bernard Asimeng, ${ }^{2}$ \\ David Dodoo-Arhin, ${ }^{1}$ and Martin Egblewogbe ${ }^{3}$ \\ ${ }^{1}$ Department of Materials Science and Engineering, School of Engineering Sciences, University of Ghana, Legon, Accra, Ghana \\ ${ }^{2}$ Department of Biomedical Engineering, School of Engineering Sciences, University of Ghana, Legon, Accra, Ghana \\ ${ }^{3}$ Department of Physics, University of Ghana, Legon, Accra, Ghana
}

Correspondence should be addressed to David Sasu Konadu; dskonadu@ug.edu.gh

Received 24 May 2021; Accepted 1 September 2021; Published 18 September 2021

Academic Editor: Rabia Rehman

Copyright (c) 2021 Ebenezer Annan et al. This is an open access article distributed under the Creative Commons Attribution License, which permits unrestricted use, distribution, and reproduction in any medium, provided the original work is properly cited.

\begin{abstract}
Dyes used by the textile, tannery, and food industries tend to pollute water bodies and must be removed to get clean water. Hydroxyapatite (HAP) was synthesized from eggshells using the wet precipitation process. The as-synthesized HAP was characterized using Fourier Transform Infrared (FTIR) and X-ray powder diffraction (XRD). The synthesized HAP was mixed with three different clays: halloysite (HNT), kaolinite (KAO), and bentonite (BENT). The removal efficiency values of methylene blue (MB) from the data showed that HAP-BENT adsorbents had higher values, followed by HAP-HNT and then HAP-KAO adsorbents. The combined masses of $24 \mathrm{mg}, 34.5 \mathrm{mg}$, and $33 \mathrm{mg}$ (representing 20\%,15\%, and 10\% of HAP-BENT mass) had average adsorption capacity values of $20.7 \mathrm{mg} / \mathrm{g}, 17.2 \mathrm{mg} / \mathrm{g}$, and $17.9 \mathrm{mg} / \mathrm{g}$, respectively. For each mass percentage, the adsorption capacity values were found to decrease with adsorbent dosage. The HAP-BENT composites had removal efficiency values of 98.4 , $91.9 \%$, and $91.9 \%$, respectively. Adsorption data for the HAP-BENT adsorbents were found to be well described by the Langmuir isotherm model and pseudo-second-order kinetic model. The effect of temperature on adsorption capacity was evaluated and thermodynamical modeling was undertaken. The thermodynamical modeling predicts that based on the value of the change in enthalpy and Gibbs free energy the process was exothermic and spontaneous. This work confirms the potential of HAP-clay composites in removing $\mathrm{MB}$ from water.
\end{abstract}

\section{Introduction}

The textile, tannery, and food industries utilize dyes in most of their production processes. The majority of these dyes tend to generate toxins and carcinogens when they are not treated before being discharged into the environment [1]. Since most dyes do not degrade biologically, measures have to be put in place in order to contain and control them to prevent pollution problems [2]. Dyes and other pollutants found in water sources do not only pose a threat to aquatic life but also endanger human health when found in drinking water sources $[3,4]$. For most people, the water quality is greatly affected by how the water looks, as such color is the first contaminant to be observed in wastewater. Even a very small quantity of dyes (less than $1 \mathrm{ppm}$ ) in water is easily visible, undesirable, and harmful [5-7]. Methylene blue (MB) is a commonly used dye for dying textiles such as cotton, wool, and silk. It can cause eye burns leading to a permanent eye injury in humans and animals. Besides eye burns, when inhaled, it can cause short rapid breaths or even difficulty in breathing [8].

Researchers have shown that several conventional methods and remediation methods to treat these polluted water sources are often not effective in dye removal [9]. The 
use of adsorbents to remove pollutants from water has been proven to be efficient and reliable especially when the adsorbent is abundant and economical [10]. Activated carbon is an adsorbent frequently used despite its relatively high price. Activated carbon has a well-developed pore structure, large surface area, and high degree of surface reactivity and so is mostly used to remove water pollutants [11].

In recent years, clay minerals have been used for their potential to adsorb both inorganic ions and organic molecules. Studies have been carried out on interactions between MB and clay particles [12-14], and it has been established that clay minerals show a strong affinity for MB. Bagane and Guiza [15] showed that clay is able to remove MB due to its high surface area as it showed an adsorption capacity of $300 \mathrm{mg} / \mathrm{g}$. Almeida et al. [16] used montmorillonite to remove MB from synthetic wastewater. It was reported that as an effective adsorbent, equilibrium was attained in less than 30 minutes. Kaolin as a dye adsorbent was also studied by Ghosh and Bhattacharyya [14] who showed that $\mathrm{NaOH}$ was able to improve its adsorption capacity through purification and treatment.

Also, hydroxyapatite (HAP; $\mathrm{Ca}_{10}\left(\mathrm{PO}_{4}\right)_{6}(\mathrm{OH})$ ) is explored in the removal of $\mathrm{MB}$ from aqueous suspension [17]. HAP is classified as a bioceramic that has a chemical resemblance to the inorganic mineral composition of hard tissues like teeth and bones in mammals. HAP can be synthesized using methods such as hydrolysis, hydrothermal, or precipitation methods, dry process, and sol-gel technique. The wet precipitation method is preferred because only water is produced as a by-product. Also, the risk of contamination during processing is low, leading to the formation of high purity crystals, and it is cheap [18]. This research adopts the wet precipitation method for the HAP synthesis (considering the advantages: affordability, high chemical and thermal stability, ionic exchange capacity, and adsorption affinity) and, consequently, forms composites with clay minerals for the MB removal from water [19-21].

Recently, the use of HAP composites for some environmental pollutant removal has also been reported [22-24], but the efficacy of HAP-clay adsorption of dyes has been rarely reported [21, 25, 26]. In this research, HAP powder is synthesized from chicken eggshells, mixed with clay minerals, and then used to explore their removal efficiencies in the removal of $\mathrm{MB}$ dye from water.

\section{Materials and Methods}

Analytical grade chemicals used were obtained from SigmaAldrich, United Kingdom. The clays were acquired from Sigma-Aldrich and used in their form without any modification except where stated. These clays are halloysite (particle size $1-3 \mu \mathrm{m}$ ), bentonite clay (particle size $\leq 25 \mu \mathrm{m}$ ), and kaolinite (particle size $\leq 25 \mu \mathrm{m}$ ). HAP was synthesized from chicken eggshells which were collected from the Madina market in Accra, Ghana.

2.1. Preparation of Hydroxyapatite. Distilled water was used to wash the eggshells which ensured the removal of all fecal matter and other foreign materials were removed. The cuticle layer inside each eggshell was then removed and washed again with distilled water. The eggshells were mechanically crushed by hand into smaller fragments to facilitate sun-drying for a week. The sun-dried eggshells were further dried in an oven for one hour at a temperature of $105^{\circ} \mathrm{C}$ to ensure thorough removal of water and then pulverized into a fine powder using a mortar and pestle after which sieving was done with a $180 \mu \mathrm{m}$ sieve. The eggshell powder was then calcined in a muffle furnace for two hours at a temperature of $900^{\circ} \mathrm{C}$. This process converted the primary constituent in the eggshell powder which was $\mathrm{CaCO}_{3}$ into $\mathrm{CaO}$. Figure 1 shows the main steps in the preparation of the eggshells to calcined egg powder.

$0.5 \mathrm{M} \mathrm{Ca}(\mathrm{OH})_{2}$ solution was measured into a $250 \mathrm{ml}$ beaker and stirred intensely at $600 \mathrm{rpm}$ on a hot plate for an hour at $90^{\circ} \mathrm{C}$, after which $100 \mathrm{ml}$ of $0.3 \mathrm{M} \mathrm{H}_{3} \mathrm{PO}_{4}$ solution was added dropwise to the $\mathrm{Ca}(\mathrm{OH})_{2}$ solution at $90^{\circ} \mathrm{C}$. The stirring continued for another one hour, after which the resulting mixture was allowed to cool. The $\mathrm{pH}$ of the mixture was adjusted to 10 by adding few drops of $1 \mathrm{M}$ ammonium hydroxide $\left(\mathrm{NH}_{4} \mathrm{OH}\right)$. The mixture was covered with aluminum foil and allowed to age for 48 hours. The $\mathrm{pH}$ was checked periodically to ensure it remained at 10 . After the aging process, the precipitate was filtered using a conical flask, funnel, and filter paper. The precipitate was then ovendried at $110^{\circ} \mathrm{C}$ for an hour and then calcined at $900^{\circ} \mathrm{C}$ for two hours to produce the HAP powder. Figure 2 shows the processes described.

2.2. Preparation of Adsorbents. The adsorbents were in powdered form. The synthesized HAP was mixed with various clay types-halloysite, kaolin. and bentonite. The masses of the clay types were $20 \%, 15 \%$. and $10 \%$ of the weight of the HAP in the respective experiments. The HAPclay mineral was mixed thoroughly and further heated to $110^{\circ} \mathrm{C}$ in an oven to remove all moisture prior to the adsorption experiment. Table 1 presents details of the batches undertaken for HAP-clay mineral composites.

2.3. Characterization of Adsorbents. Fourier Transform Infrared (FTIR) and X-ray powder diffraction (XRD) were used to characterize the synthesized HAP sample. FTIR analysis was performed with Bruker (PerkinElmer, Frontier, Perkin Elmer, Ohio, USA), and the XRD was carried out using a PANalytical Empyrean (Series 2) powder diffractometer (PANalytical B.V., Lelyweg 1, 7602 EA, Almelo, The Netherlands). The XRD was equipped with a copper-target tube and was operated at $45 \mathrm{kV}$ and $40 \mathrm{~mA}$ to give the $\mathrm{Cu}-\mathrm{K} \alpha$ line at a wavelength of $15.406 \mathrm{~nm}$. The $K_{\beta}$ line was removed with a nickel filter. The analysis of the XRD patterns was carried out on the Panalytical HighScore Plus software (v. 4.8) and with the ICDD PDF-4/Organics 2020 database.

2.4. Batch Adsorption Experiments. The adsorption experiment was performed in a beaker using a $5 \mathrm{mg} / \mathrm{L} \mathrm{MB}$ dye solution. Initially, the experiment was undertaken using mixtures of HAP and HNT (mass is equivalent to $20 \%$ of 

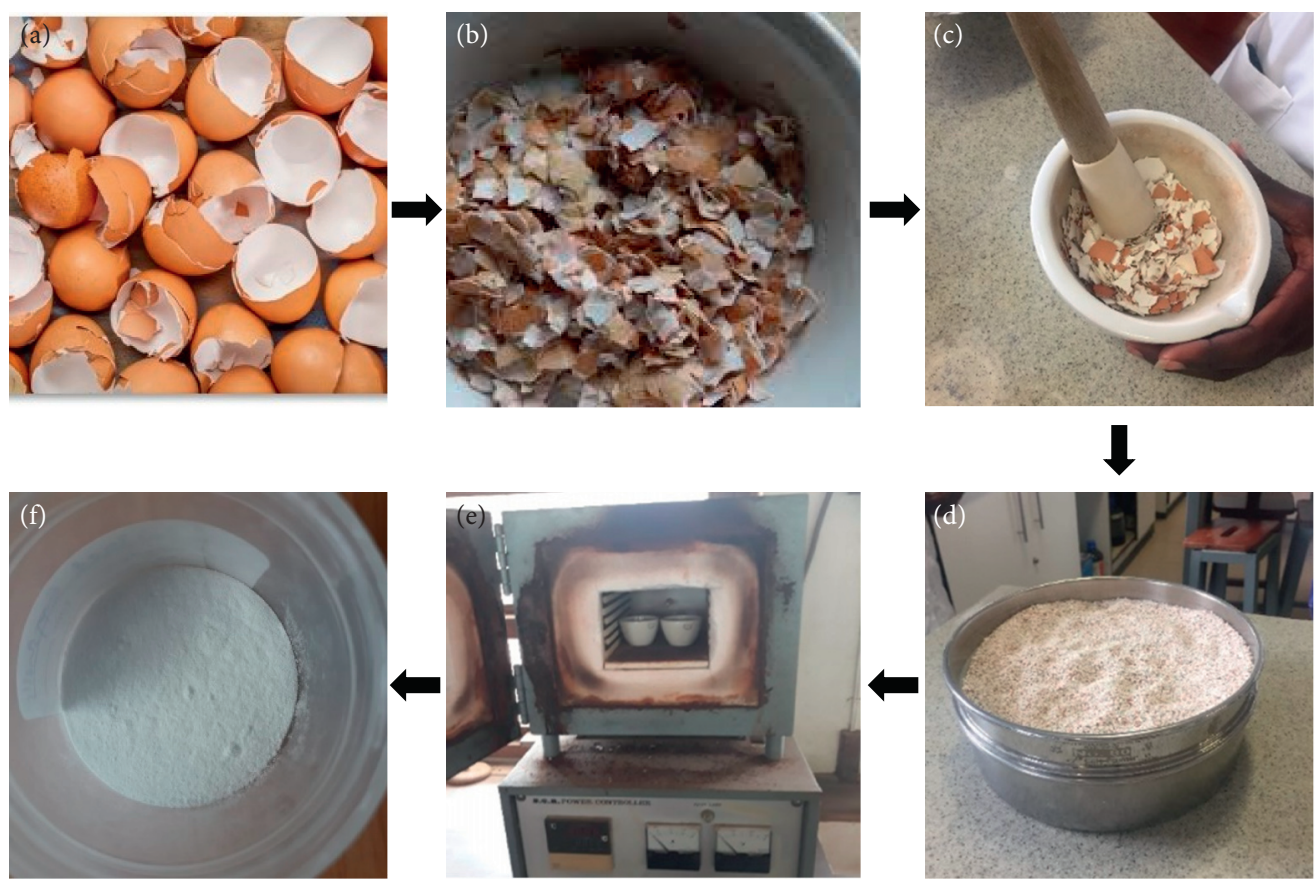

Figure 1: Powder preparation steps of calcined eggshells. (a) Eggshell. (b) Sun-drying. (c) Grinding. (d) Sieving. (e) Calcination. (f) Filtration.

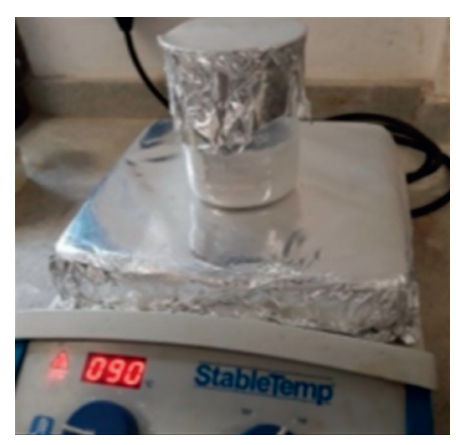

(a)

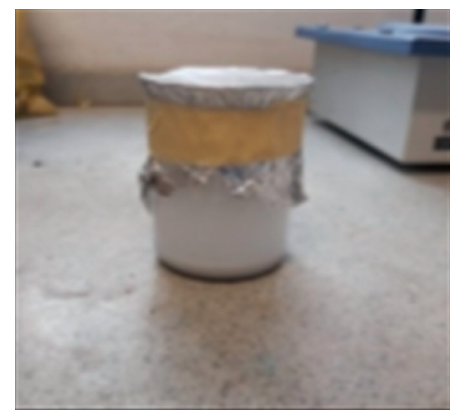

(d)

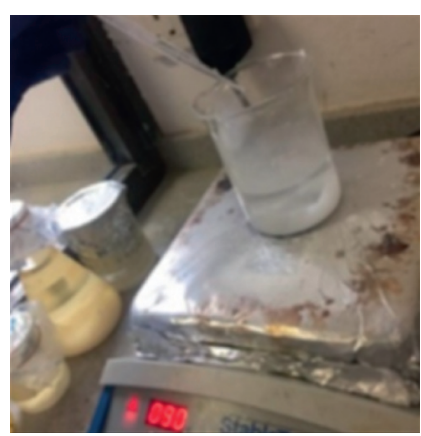

(b)

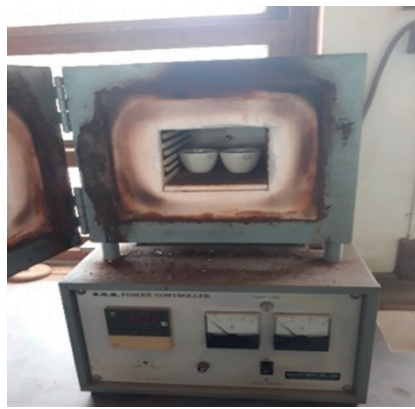

(e)

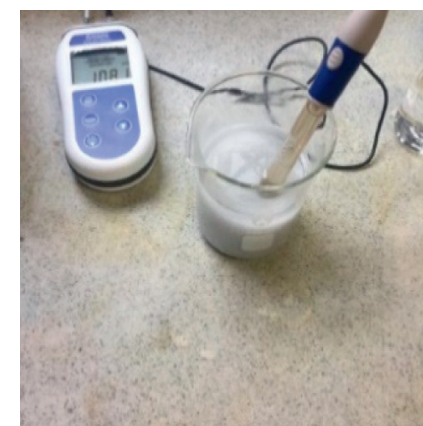

(c)

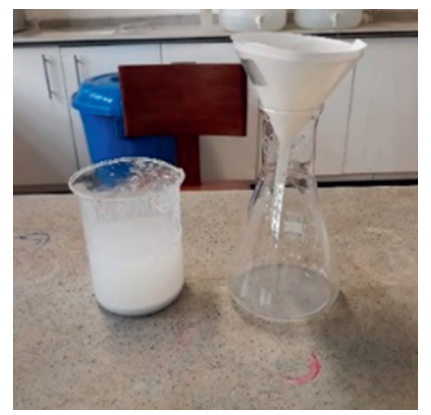

(f)

Figure 2: Steps in the preparation of HAP from calcined powdered eggshells. (a) Heating and stirring. (b) Acid addition. (c) pH measurement. (d) Aging. (e) Calcination. (f) Filtration.

HAP). This was followed by other mixtures (for HAP-BENT and HAP-KAO) as given in Table 1. The beaker containing the solution and adsorbent was placed on a magnetic stirrer plate to ensure continuous mixing for the allowed time stated in Figure 1. After that, Whatman 1 filter paper with a pore size of $11 \mu \mathrm{m}$ was used to filter the solution. The absorbance of the resulting solution was analyzed using a UVVIS spectrophotometer (ThermoScientific Genesys) at $668 \mathrm{~nm}$ wavelength to determine the absorbance of the $\mathrm{MB}$ dye in the filtrate. The concentration of the remaining $\mathrm{MB}$ 
TABLE 1: Experimental batches for HAP-clay mixtures.

\begin{tabular}{lccc}
\hline \multirow{2}{*}{ Mass of HAP $(\mathrm{mg})$} & \multicolumn{2}{c}{$\begin{array}{c}\text { Mass of each clay mineral }(\mathrm{mg}) \\
\text { 2nd set: } 15 \% \text { HAP mass }\end{array}$} & 3rd set: $10 \%$ HAP mass \\
\hline 20.0 & 1st set: 20\% HAP mass & 3 & 2 \\
30.0 & 6 & 4.5 & 3 \\
40.0 & 8 & 6 & 4 \\
50.0 & 10 & 7.5 & 5 \\
60.0 & 12 & 9 & 6 \\
70.0 & 14 & 10.5 & 7 \\
80.0 & 16 & 12 & 8 \\
90.0 & 18 & 13.5 & 9 \\
100.0 & 20 & 15 & 10 \\
\hline
\end{tabular}

was calculated from the measured absorbance. The experiment was repeated with HNT with masses equivalent to $15 \%$ and $10 \%$ of HAP in combination with HAP (Table 1). The different adsorption dosages $(20 \%, 15 \%$, and $10 \%$ of the HAP-given masses for clay masses) were repeated for KAO and BENT.

To further investigate kinetics and isotherm models, the repetition of the adsorption experiments was done for different adsorption times, every 30 minutes for the mass combinations that resulted in the highest adsorption capacity. HAP:BENT composite mass combinations were further investigated ( $(20 \mathrm{mg}: 4 \mathrm{mg})$ and $(30 \mathrm{mg}: 4.5 \mathrm{mg})$ and (30 mg: $3 \mathrm{mg})$ ). Each combined mass of adsorbent was to remove $\mathrm{MB}$ ( $5 \mathrm{mg} / \mathrm{L}$ concentration solution) allowing 30 minutes of contact time. This was undertaken every 30 minutes till the 300 minutes ( 5 th) hour) of contact time for adsorbent and measured MB solution. The adsorption data was analyzed to understand the mechanisms via fitting to the two main isotherm models: Freundlich and Langmuir isotherm models. The initial $\mathrm{pH}$ in the range 5.5-7.5 was used for the experiments and at a constant temperature of $(25 \pm 1)^{\circ} \mathrm{C}$. The basic Freundlich and Langmuir isotherms model fittings were done, and the key parameters were computed. The adsorption capacity, $q$, which was the amount of dye adsorbed was calculated using

$$
q=\left(C_{0}-C_{t}\right) \frac{V}{m}
$$

where $q$ is the dye adsorbed ( $\mathrm{mg} / \mathrm{g}$ ), $C_{0}$ is the initial concentration of dye $(\mathrm{mg} / \mathrm{L}), C_{t}$ is the concentration of dye in solution at a given time $(\mathrm{mg} / \mathrm{L}), V$ is the solution volume $(\mathrm{L})$, and $m$ is the adsorbent dosage $(\mathrm{g})$. The percentage removal is given by

$$
A \%=\left(\frac{C_{O}-C_{t}}{C_{o}}\right) \times 100,
$$

where $A \%$ is the percentage of $\mathrm{MB}$ dye removed, and the remaining parameters are defined.

2.5. Isotherm and Kinetic Modeling of Adsorption Data. The two widely used models to describe isotherm processes in adsorption are Freundlich and Langmuir models. The Langmuir equation assumes that the maximum adsorption takes place when the surface is covered by adsorbate in a monolayer while the Freundlich model is empirical [11, 27]. Again, the Langmuir model assumes that the point of valance exists on the surface of the adsorbent and that each of these sites is capable of adsorbing one molecule. Furthermore, it is assumed that the adsorption sites have equal affinities for molecules of adsorbate and that the presence of adsorbed molecules at one site will not affect the adsorption of molecules at an adjacent site [28, 29].

The original and linear forms of the Langmuir and Freundlich equations are given in equations (3) and (4), respectively.

$$
\begin{gathered}
\text { original form : } q_{e}=\frac{q_{m} * K_{L} * C_{e}}{1+K_{L} * C_{e}}, \\
\text { linear form }: \frac{C_{e}}{q_{e}}=\frac{1}{K_{L} q_{m}}+\frac{1}{q_{m}} * C_{e}, \\
\text { original form }: q_{e}=K_{F} * C_{e}^{1 / n}, \\
\text { linear form }: \log q_{e}=\log K_{F}+\frac{1}{n} \log C_{e},
\end{gathered}
$$

where $K_{L}$ and $q_{m}$ are Langmuir constant and maximum adsorption capacity $(\mathrm{mg} / \mathrm{g})$, respectively, $q_{e}$ is the equilibrium adsorption capacity $(\mathrm{mg} / \mathrm{g}), K_{F}$ and $(1 / n)$ are the Freundlich constant, respectively, and $C_{e}$ is the equilibrium concentration $(\mathrm{mg} / \mathrm{L})$.

The process kinetics described the solute uptake rate thereby allowing the estimated residence time required to achieve a definite extent of MB removal [29, 30]. The adsorption kinetic models used in this work are the pseudofirst-order (PFO) and the pseudo-second-order (PSO) rate equations and were both fitted to the experimental data. The pseudo-first-order equation assumes that the rate of change in solute adsorption over time is directly proportional to the difference in saturation concentration and the amount of adsorptive solid uptake over time [31]. The two models as used in this work are found in

$$
\begin{aligned}
\log \left(q_{e}-q_{t}\right) & =\log q_{e}-\frac{k_{1}}{2.303} t \\
\frac{t}{q_{t}} & =\frac{1}{\left(k_{2} q_{e}^{2}\right)}+\frac{t}{q_{e}}
\end{aligned}
$$

where $q_{e}$ and $q_{t}$ are the amount of $\mathrm{MB}$ adsorbed $(\mathrm{mg} / \mathrm{g})$ at equilibrium and any time $t$, respectively, and $k_{1}\left(\mathrm{~min}^{-1}\right)$ and $k_{2}\left(\mathrm{~min}^{-1}\right)$ are rate constants of adsorption for PFO and PSO, 
respectively. From equation (3), a plot of $\log \left(q_{e}-q_{t}\right)$ versus time, $t$, results in a negative slope with gradient being $\left(k_{1}\right)$ / 2.303 and $\log \left(q_{e}\right)$ intercept on the vertical axis. Also, to deduce the parameters of adsorption in equation (4), $t / q_{t}$ is plotted against $t$ with slope $\left(1 / q_{e}\right)$ and intercept $\left(1 / k_{2} q_{e}^{2}\right)$ on the vertical $(t)$ axis.

2.6. Thermodynamical Modeling. Thermodynamic parameters, including Gibbs free energy change $\left(\Delta G^{\circ}\right)$, enthalpy change $\left(\Delta H^{\circ}\right)$, and entropy change $\left(\Delta S^{\circ}\right)$, serve to evaluate the effect of temperature on the adsorption of $\mathrm{MB}$ onto adsorbents and provide in-depth information regarding the inherent energy changes associated with the adsorption process [32]. These parameters are calculated from equations (7)-(9):

$$
\Delta G^{\circ}=-\mathrm{RTLnK}_{\mathrm{L}}{ }^{\circ},
$$

where $R$ is the universal gas constant $(8.314 \mathrm{~J} / \mathrm{mol} \cdot \mathrm{K}), T$ the temperature $(\mathrm{K})$, and $K_{L}^{\circ}$ the (dimensionless) 'thermodynamic' Langmuir constant for the adsorption process.

$$
\begin{aligned}
\operatorname{Ln} K_{L}^{\circ} & =\left(\frac{\Delta S^{\circ}}{\mathrm{R}}\right)-\left(\frac{\Delta \mathrm{H}^{\circ}}{\mathrm{RT}}\right), \\
\Delta G^{\circ} & =\Delta \mathrm{H}^{\circ}-\mathrm{T} \cdot \Delta \mathrm{S}^{\circ} .
\end{aligned}
$$

\section{Results and Discussion}

3.1. Characterization of Adsorbents. The results of the FTIR analysis of synthesized HAP samples are plotted in Figure 3(a) for the calcined hydroxyapatite (cHAP) and crushed or powdered eggshell (EggS) samples. The carbonate functional group showed up within the range $1395-1600 \mathrm{~cm}^{-1}$ ( 23 ; asymmetric stretch vibration) and $873-889 \mathrm{~cm}^{-1}$ ( $\nu 2$; out-of-plane bend vibration). The crushed eggshell showed this carbonate functional group at $1026 \mathrm{~cm}^{-1}$. In the cHAP spectrum, there was a peak of the $\mathrm{PO}_{4}{ }^{3-}$ functional group at $1065 \mathrm{~cm}^{-1}$ vibrational frequency [33]. The spectrum also showed the presence of $\mathrm{CO}_{3}{ }^{2-}$ peaks at $895 \mathrm{~cm}^{-1}$ and $1361 \mathrm{~cm}^{-1}$ for cHAP, and the respective carbonate functional groups for the EggS were observed at $874 \mathrm{~cm}^{-1}$ and $1065 \mathrm{~cm}^{-1}$ [34]. There was a clear reduction in intensity for the carbonate functional group after calcination, and an increase in intensity for the phosphate functional group (at $1026 \mathrm{~cm}^{-1}$ ) was observed. The presence of the $\mathrm{OH}^{-}$functional group observed at $3642 \mathrm{~cm}^{-1}$ for EggS disappeared after calcination.

The FTIR spectra for the clays are plotted in Figure 3(b). The bands 3550 to $4000 \mathrm{~cm}^{-1}$ were the structural hydroxyl groups in addition to the water molecules in the interlayer space of the raw bentonite. The FTIR spectrum in the lower region showed bands at 1631, 1002, 900, 817, 720, and $538 \mathrm{~cm}^{-1}$, and these bands were due to the vibrational modes of the $\mathrm{SiO}_{4}$ tetrahedron of bentonite. The $\mathrm{O}-\mathrm{H}$ stretching band was at $3622 \mathrm{~cm}^{-1}$, and the intralayer $\mathrm{H}$-bonded and $\mathrm{O}-\mathrm{H}$ stretching was seen at broadband centered at $3381 \mathrm{~cm}^{-1}$. The $1631 \mathrm{~cm}^{-1}$ band was the $\mathrm{H}-\mathrm{O}-\mathrm{H}$ bending vibration of water, while the $1416 \mathrm{~cm}^{-1}$ band could be attributed to the siloxane (-Si-O-Si-) group stretching. This indicated the possibility of the hydroxyl linkage between octahedral and tetrahedral layers. Another sharp and intense $1631 \mathrm{~cm}^{-1}$ band observed was due to $\nu 2$ asymmetric $\mathrm{OH}$ stretch (deformation mode) of water and was a structural part of the mineral.

Furthermore, the FTIR spectrum for kaolinites is shown in Figure 3(b). The $3622 \mathrm{~cm}^{-1}$ band observed can be attributed to the inner hydroxyls (crystalline hydroxyl), and the bands observed around the other three characteristic bands were generally ascribed to vibrations of the external hydroxyls. The three $3693 \mathrm{~cm}^{-1}, 3645 \mathrm{~cm}^{-1}$, and $3622 \mathrm{~cm}^{-1}$ bands were the kaolinite. The $1000 \mathrm{~cm}^{-1}$ to $500 \mathrm{~cm}^{-1}$ bands were dominated by the functional groups of $\mathrm{Si}-\mathrm{O}$ and $\mathrm{Al}-$ $\mathrm{OH}$. The bands at $817 \mathrm{~cm}^{-1}$ and $720 \mathrm{~cm}^{-1}$ were said to be Siquartz whereas $1002 \mathrm{~cm}^{-1}$ and $900 \mathrm{~cm}^{-1}$ were the $\mathrm{OH}$ vibrations usually linked to $2 \mathrm{Al}^{3+}$. The main bands of the HNT were $3622 \mathrm{~cm}^{-1}, 1631 \mathrm{~cm}^{-1}, 1002 \mathrm{~cm}^{-1}$, and $900 \mathrm{~cm}^{-1}$. The $3622 \mathrm{~cm}^{-1}$ is for the O-H stretching of inner hydroxyl groups, $1631 \mathrm{~cm}^{-1}$ shows $\mathrm{O}-\mathrm{H}$ deformation of water, and $900 \mathrm{~cm}^{-1}$ was interpreted as the $\mathrm{O}-\mathrm{H}$ bending of inner hydroxyl groups $1002 \mathrm{~cm}^{-1}$ for Si-O stretching [35].

Figure 4 shows the XRD pattern obtained for the assynthesized HAP for the (a) crushed eggshells and (b) calcined samples. Most XRD patterns showed HAP diffraction peaks observed in standards and literature. The major phase in the calcined sample, as expected, was HAP, when compared with the data obtained from the ICDD reference code 01-074-4172 using the search and match protocol in HighScore Plus. From Figure 4(b), the peaks with high intensities at $2 \Theta$ equaling to $31.7681^{\circ}, 32.1784^{\circ}, 32.906^{\circ}$, and $25.8571^{\circ}$ were confirmed as HAP. The respective Miller indices (hkl) values for these peaks were (211), (112), (300), and $(002)[34,36]$. There were also peaks corresponding to calcium phosphate, $\mathrm{Ca}_{3}\left(\mathrm{PO}_{4}\right)_{2}$ (ICDD reference code 00009-0169), indicating the presence of this compound as well. The ICDD reference codes 01-089-5969, 98-015-4315, 00011-0293, and 01-009-0169 showed that these patterns corresponded to calcium hydrogen phosphate, apatite, calcium phosphate hydroxide hydrate, and calcium phosphate [36]. The effect of the calcination could be seen in the removal of some of these compounds resulting in the main hydroxyapatite phase.

3.2. Adsorbent Dose Effect. The adsorbent dose effect on the efficient removal of the $\mathrm{MB}$ dye by the HAP-clay was studied. Figures 5(b), 5(d), and 5(f) show the outcome of the effect of dosage on MB dye removal for HAP-HNT, HAPKAO, and HAP-BENT. The maximum removal efficiency of MB dye for HAP-HNT mixtures was found to be $95 \%$ for a combined mass of $120 \mathrm{mg}$. It was seen that the efficient removal for combined masses of $84 \mathrm{mg}$ and or more was at least $80 \%$. Also, the average removal efficiency for $20 \%$ mass of HAP used as HNT mass was found to be higher values than the 15 and 10 percentages. The maximum removal efficiencies obtained for $15 \%$ and $10 \%$ masses (for HNT mass) used were $80.7 \%$ and $52.7 \%$, respectively. The HAP$\mathrm{KAO}$ mixtures were found to have low removal efficiency 


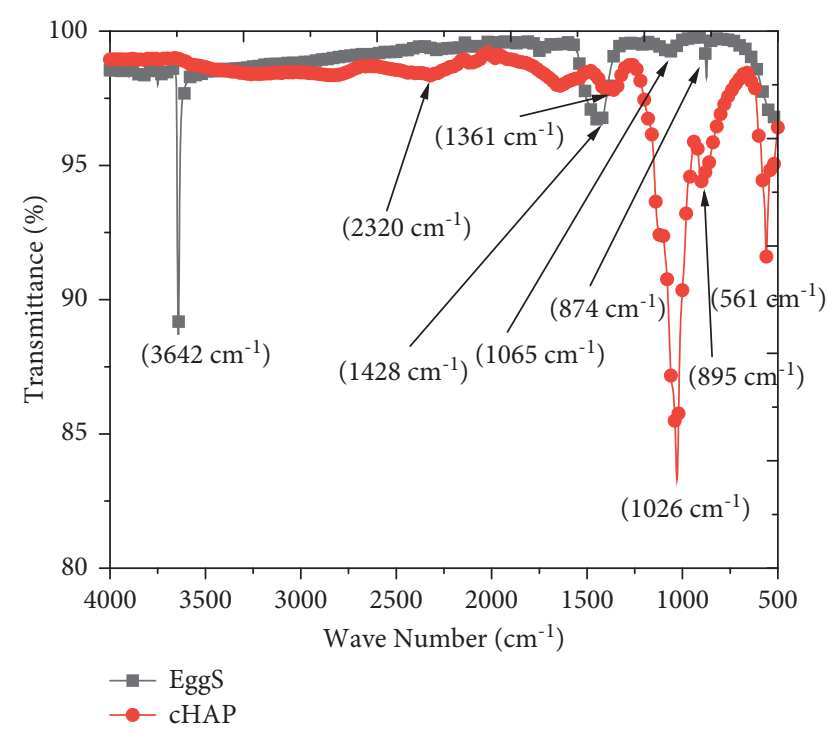

(a)

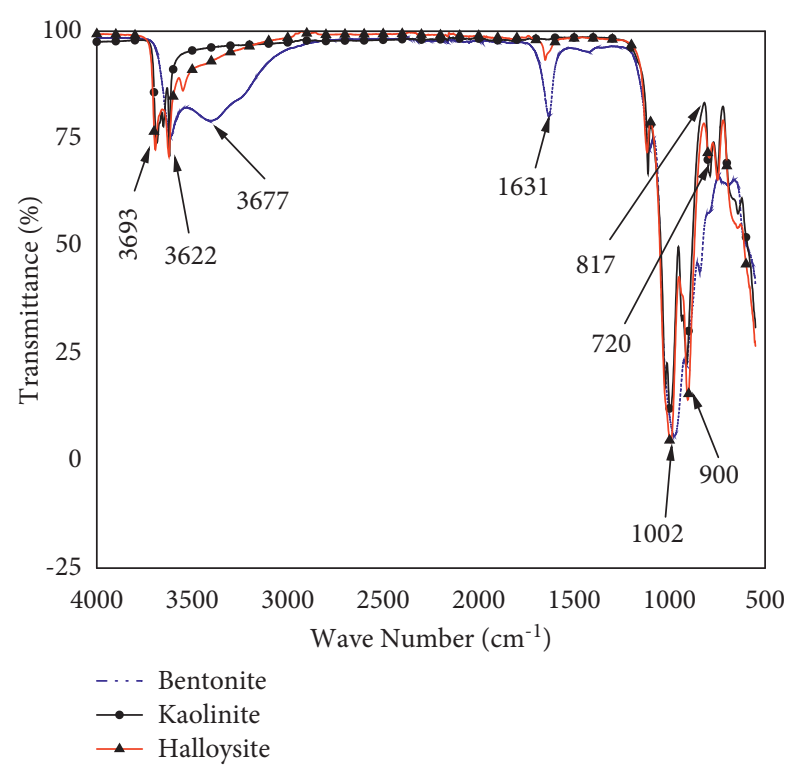

(b)

FIgURE 3: FTIR spectra for (a) powdered eggshells and calcined HAP and (b) HNT, KAO, and BENT.

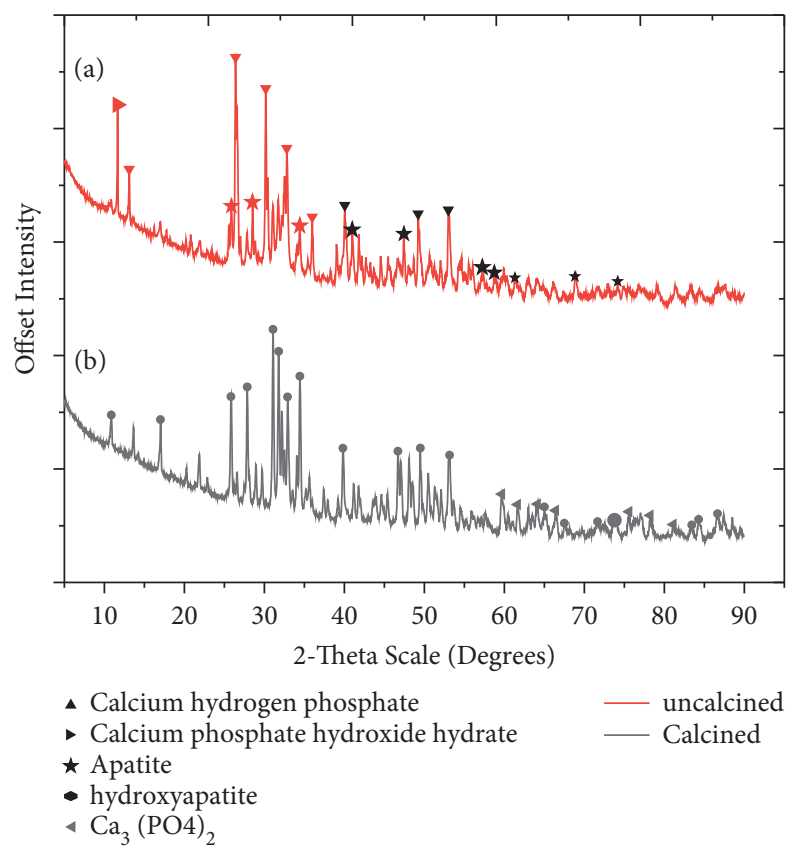

Figure 4: XRD analysis of (a) uncalcined EggS and (b) cHAP.

values (maximum value was $38.4 \%$ for $120 \mathrm{mg}$ combined mass) in comparison with the other two.

The efficiency values obtained for HAP-BENT combinations were higher in all batches in comparison with HAPHNT and HAP-KAO mixtures. For instance, in the case of $120 \mathrm{mg}$ combined mass, $98.9 \%$ removal efficiency maximum value was obtained. The calculation of average removal efficiency values for $115 \mathrm{mg}$ and $110 \mathrm{mg}$ combined masses also resulted in $95.6 \%$ for both. The average removal efficiency value for $120 \mathrm{mg}$ combined mass of HAP-BENT was
97.7\%. The minimum removal efficiency value was found to be $95.3 \%$ for HAP-BENT combined mass of $96 \mathrm{mg}$. The remaining percentages $15 \%$ and $10 \%$ of HAP-BENT both had average removal efficiency values of $91.3 \%$.

Two main trends were noted in the removal efficiency data. The first was that, for all mixtures, the increase in adsorbent dosage increases the value of the removal efficiency and that the incremental changes are not significant after the third hour of contact time. This is because, at the initial stage of adsorption, the surface of the adsorbent is 

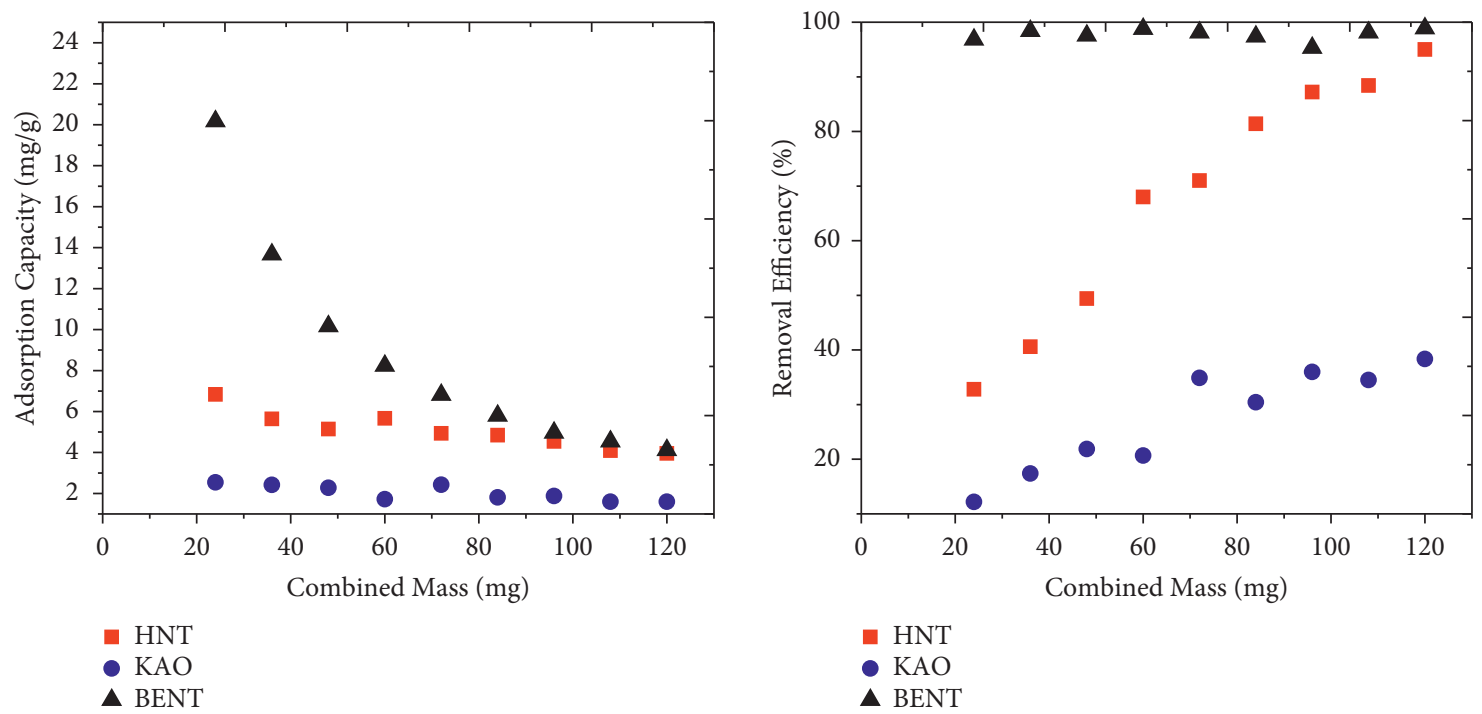

(a)
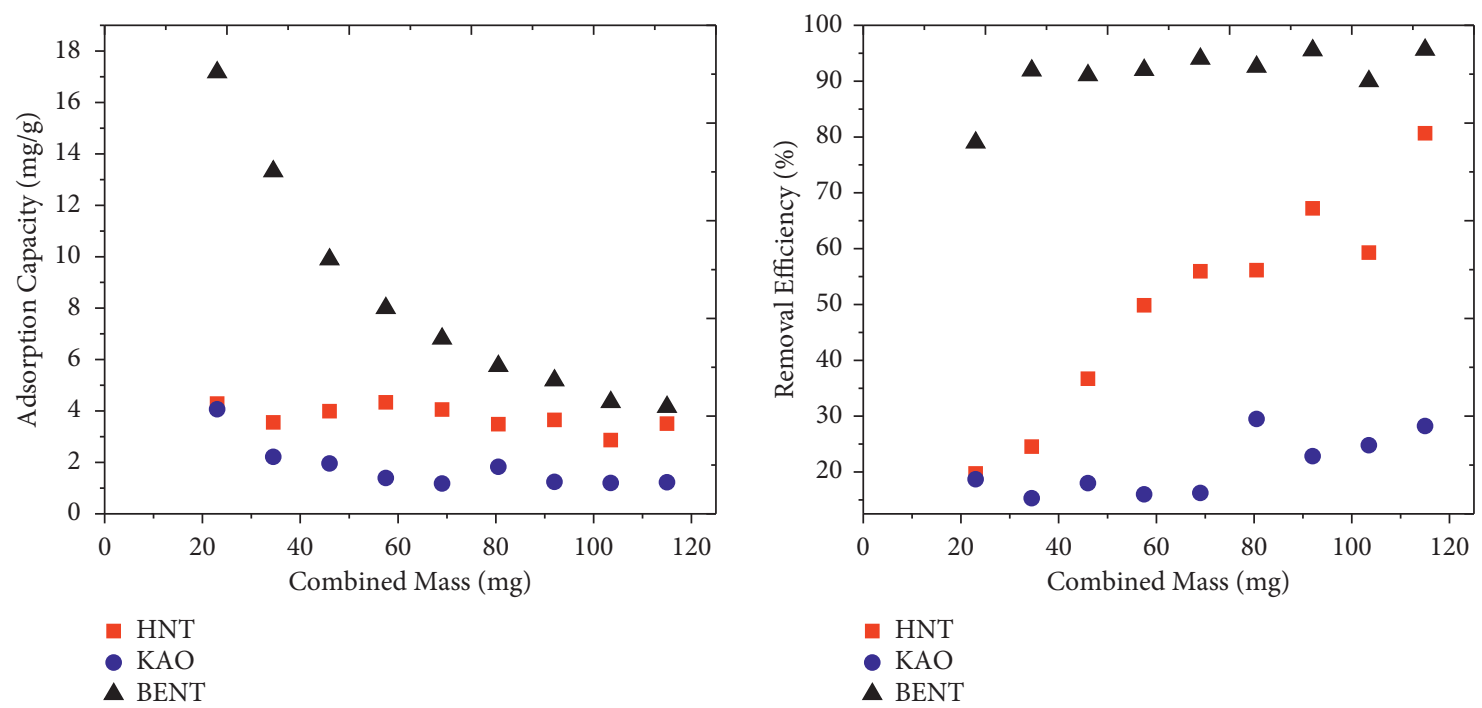

(c)

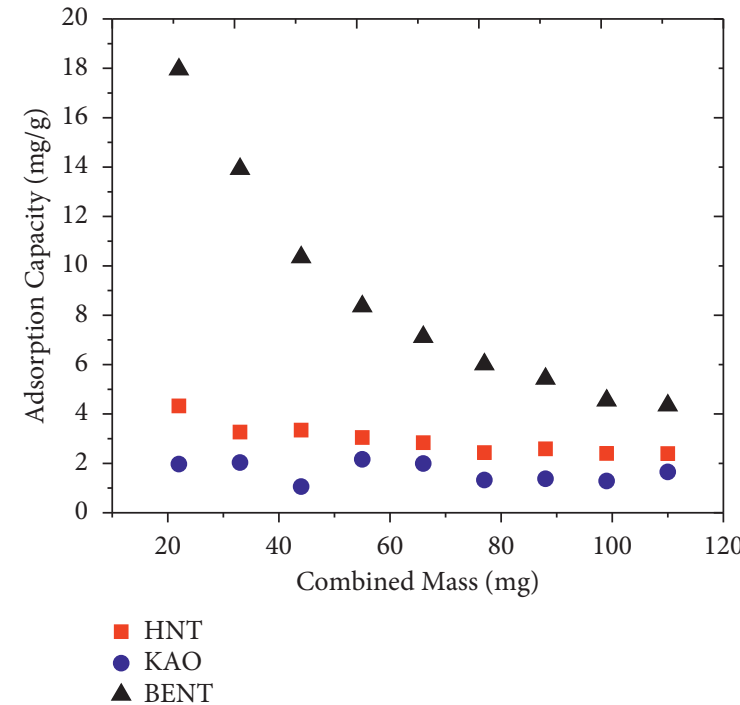

(d)

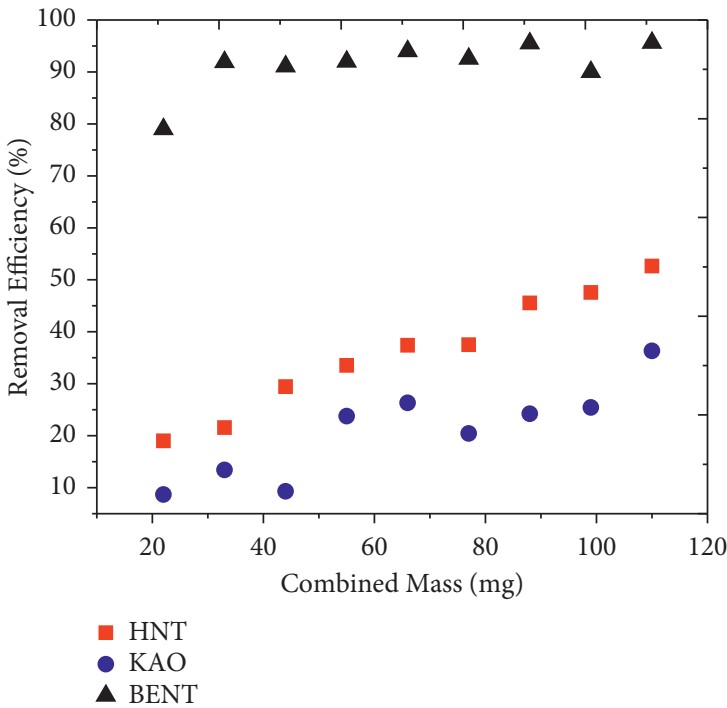

(e)

(f)

FigURE 5: Effect of adsorbent dosage on adsorption capacity and removal efficiency: (a) and (b) for 20\% HAP = Clay mass, (c) and (d) for $15 \% \mathrm{HAP}=$ Clay mass, and (e) and (f) for 10\% HAP=Clay mass. 
bare resulting in faster sorption kinetics of the adsorbate onto the surface of the adsorbent (usually through diffusion kinetics). At the later stage of the adsorption process, the main kinetics changes from a diffusion process to more of an attachment-controlled process [37].

The second trend observed was that the removal efficiency values for HAP-BENT adsorbents were higher than HAP-KAO and HAP-HNT composites in adsorption processes. Also, the adsorption capacity values were found to be the highest with the HAP-BENT combinations. The combined adsorbent masses of $24 \mathrm{mg}, 23 \mathrm{mg}$, and $22 \mathrm{mg}$ (which represents $20 \%, 15 \%$, and $10 \%$ of HAP mass) had adsorption capacity values of $20.2 \mathrm{mg} / \mathrm{g}, 17.2 \mathrm{mg} / \mathrm{g}$, and $17.9 \mathrm{mg} / \mathrm{g}$, respectively. For each percentage, the adsorption capacity values were found to be decreasing with adsorbent dosage. Considering the values of the removal efficiency and the adsorption capacities, the best adsorbent for each category of adsorbent HAP: BENT was selected. The adsorption capacity values $20.17 \mathrm{mg} / \mathrm{g}, 13.32 \mathrm{mg} / \mathrm{g}$, and $13.92 \mathrm{mg} / \mathrm{g}$ for $20 \%, 15 \%$, and $10 \%$ (of HAP mass used as bentonite mass), respectively, were found to be associated with removal efficiency values $97 \%, 92 \%$, and $92 \%$ for the respective percentages. This proposes that the best performance in terms of the adsorptive capacity and removal efficiency was $24 \mathrm{mg}$ combined mass (HAP mass $=20 \mathrm{mg}$ and BENT mass $=4 \mathrm{mg}$ ) which was associated with 20\% HAP-BENT adsorbent composite. The combined masses of $34.5 \mathrm{mg}$ (HAP mass $=30 \mathrm{mg}$ and BENT mass $=4.5 \mathrm{mg}$ ) and $33 \mathrm{mg}$ (HAP mass $=30 \mathrm{mg}$ and BENT mass $=3 \mathrm{mg}$ ) representing $15 \%$ and $10 \%$ HAP -BENT composites were the best performers in their respective adsorption processes.

The adsorption capacity values for all combinations are also plotted in Figures 5(a), 5(c), and 5(e). A similar trend was observed for all combinations. There is a decrease in adsorption capacity values as the adsorbent dosage increases. This observation which was the decrease in adsorption capacity values could be described by two reasons. These were as follows: (1) the available active sites are utilized at low adsorbent dose compared to high adsorbent dose in which too many sites are available for a limited quantity of adsorbate, and (2) high adsorbent dose causes low equilibrium $\mathrm{MB}$ concentration as a reduced driving force for adsorption occurs. The same trends were reported by Salvestrini et al. [32] for laterite and $\mathrm{Wu}$ et al. [33] for pyrophyllite [38,39]. Wu et al. [33] said the possible aggregation, overlapping, and overcrowding of adsorbent contributed to the reduction to a decrease in adsorption capacity due to the decreased available surface area [39].

3.3. Effect of Contact Time. The effect of contact time is crucial to understand the binding processes of $\mathrm{MB}$ dye and the equilibrium time which strongly depends on factors like pore structure of adsorbent, adsorbent particle size or surface area, and adsorbent concentration. The efficient removal of $\mathrm{MB}$ results obtained as a function of contact time for $24 \mathrm{mg}$ combined adsorbent mass (20 mg HAP: $4 \mathrm{mg}$ BENT) is presented in Figure 6. The average removal efficiency for the $24 \mathrm{mg}$ combined adsorbent mass (20 mg HAP :
$4 \mathrm{mg}$ BENT) was $98.1 \%$ with a maximum value of $99.4 \%$ (at the 5 th hour of contact time). The minimum removal efficiency value for the $24 \mathrm{mg}$ combined mass HAP-BENT was 96.2\% (at 30 minutes of contact time).

Generally, for all adsorbents of HAP-BENT, removal efficiency values increased with increasing contact time with marginal increases from the third hour of contact time. The best performer in terms of both removal efficiency and adsorptive capacity for HAP-BENT adsorbents with combined masses of $24 \mathrm{mg}, 34.5 \mathrm{mg}$, and $33 \mathrm{mg}$ was $98.7 \%$ (at 90 minutes of contact time), $98.7 \%$ (at 210 minutes of contact time), and $99.2 \%$ (at 90 minutes of contact time), respectively. The minimum removal efficiency values for HAPBENT adsorbents with $24 \mathrm{mg}, 34.5 \mathrm{mg}$, and $33 \mathrm{mg}$ were $96.2 \%$ (at 20 minutes of contact time), $96.5 .0 \%$ (at 180 minutes of contact time), and $84.6 \%$ (at 300 minutes of contact time). This observation suggests that the adsorption of $\mathrm{MB}$ dye under this study is time-dependent and that the significant increase from 20 minutes of contact time to 150 minutes for all adsorbents could be due to the initial vacant absorbent sites and the concentration gradient of the solute was high [40].

Ion-exchange processes dominate the adsorption of $\mathrm{MB}$ on clay minerals. Thus, the sorption capacity can vary strongly with $\mathrm{pH}$ [41]. Al-Ghouti et al. [41] showed that the mechanism of adsorption of dye onto diatomite was due to physiosorption (depending on the particle size) and electrostatic interactions (depending on the $\mathrm{pH}$ used) [41]. The adsorption of dyes unto HAP adsorbent was also noted to be highly dependent on ion exchanges and strongly dependent on $\mathrm{pH}$. According to Allam et al. [20], the adsorption of MB as a cationic dye on the adsorbent microwave-HAP could be explained as follows: the electrostatic attraction between the negatively charged surface of the microwave-HAP and the positively charged group of the dye was more important at $\mathrm{pH}$ above 7.2 [20]. On the contrary, electrostatic repulsions in an acidic medium occurred between positively charged surface sites on microwave-HAP and MB cations, and this does not favor the adsorption of $\mathrm{MB}$. Indeed, there was a competition between excess protons $\left(\mathrm{H}^{+}\right)$and $\mathrm{MB}$ cations for active adsorption sites in microwave-HAP when the solution was acidic and resulted in lower adsorption [20]. A similar observation has been reported elsewhere [42]. The adsorption capacity of microwave-HAP was reported as $33.3 \mathrm{mg} / \mathrm{g}$ while raw HAP was $0.7 \mathrm{mg} / \mathrm{g}$ [20]. Table 2 shows the summary of related adsorbents and their respective adsorption capacity. The effect of time on adsorption capacity and removal efficiency for a combined optimum mass of the composites varied is shown in Figure 6. In this investigation, the $\mathrm{pH}$ of the composite was not altered and stayed within 5.5-7.0. It is, therefore, proposed that the mechanism for the composite adsorbent will be dominated by clay adsorption of MB.

3.4. Adsorption Isotherm and Kinetic Models. The best performers in the three sets of weight percentages have their data fitted to the Langmuir model in Figures $7(\mathrm{a})-7(\mathrm{c})$ and the Freundlich in Figures 8(a)-8(c). The key parameters of 


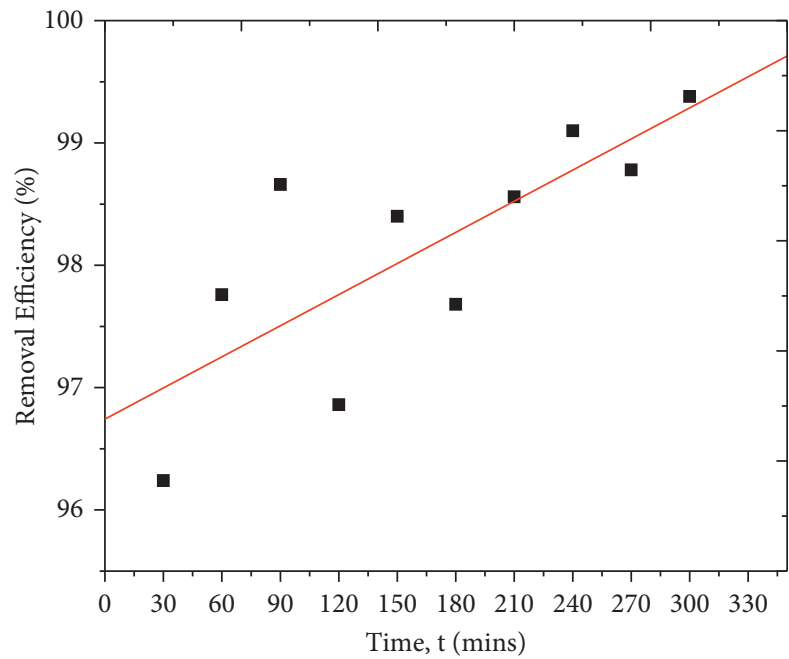

(a)

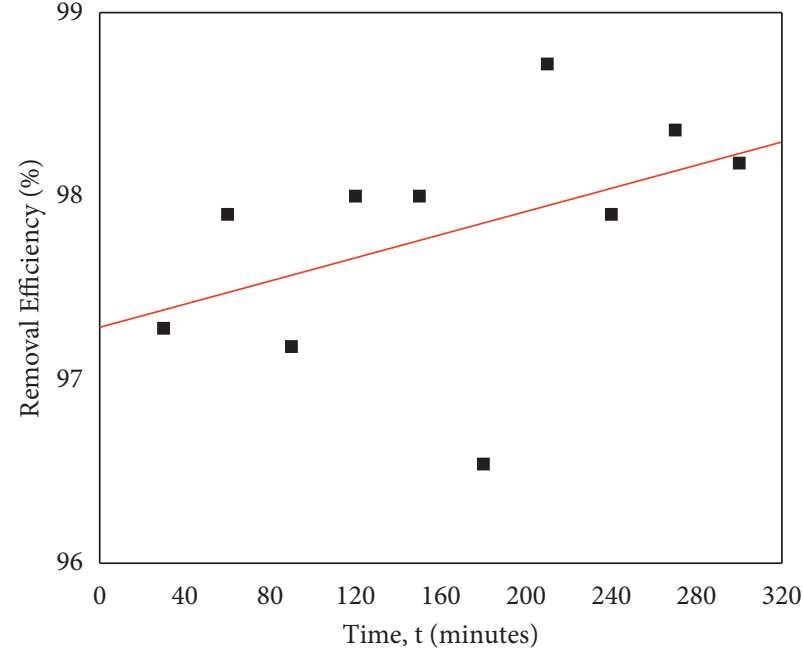

(b)

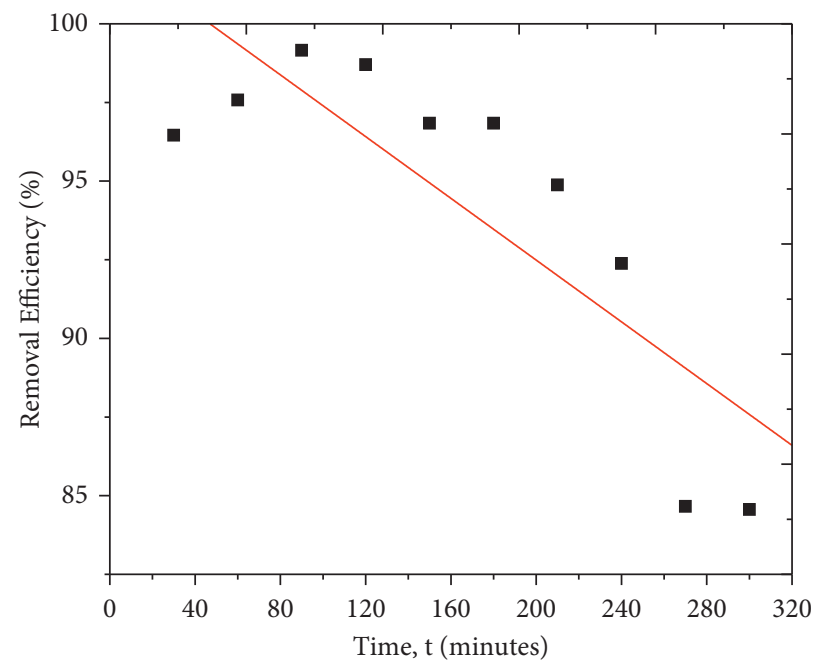

(c)

FIGURE 6: Effect of contact time on adsorption capacity for (a) 24 mg combined adsorbent mass, (b) 34.5 mg combined adsorbent mass, and (c) $33 \mathrm{mg}$ combined adsorbent mass.

TABLE 2: Adsorption capacities for some related adsorbents.

\begin{tabular}{lcc}
\hline Adsorbent & $\begin{array}{c}\text { Adsorption } \\
\text { capacity }(\mathrm{mg} / \mathrm{g})\end{array}$ & Reference \\
\hline Raw kaolin & 8.8 & {$[14]$} \\
Raw kaolin & 7.59 & {$[14]$} \\
NaOH treated pure kaolin & 20.49 & {$[14]$} \\
NaOH treated raw kaolin & 16.34 & {$[14]$} \\
Clay & 6.3 & {$[12]$} \\
Bentonite & $151-175$ & {$[14]$} \\
HAP & 14.3 & {$[43]$} \\
HAP:Bentonite mix & 20.70 & This research \\
\hline
\end{tabular}

the two models were computed and presented in Table 3. The $R$-square values for HAP-BENT composites $24 \mathrm{mg}, 34.5 \mathrm{mg}$, and $33 \mathrm{mg}$ were found to be $0.99,1.00$, and 0.99 , respectively, for the Langmuir model fit. These values were greater than the R-square values from the Freundlich isotherm model fitting. This implies that the adsorption data for the HAPBENT-24 mg, $34.5 \mathrm{mg}$, and $33 \mathrm{mg}$ combined masses can be described with the Langmuir isotherm model.

The values obtained for the separation factor, $R_{L}$, confirm this deduction. The expression for the dimensionless quantity, separation factor, $R_{L}$, is defined as

$$
R_{L}=\frac{1}{1+K_{L} * C_{0}},
$$

where $C_{0}$. refers to the initial concentration of the adsorbate in $(\mathrm{mg} / \mathrm{L})$ and $K_{L}$ is the Langmuir constant which is related to the adsorption capacity in $(\mathrm{mg} / \mathrm{g})$. It is worthy to note that a variation of the suitable area and the porosity of the adsorbent can be correlated with $K_{L}$, implying the fact that higher adsorption capacity can be because of large surface area and pore volume. The $R_{L}$ values for all HAP-BENT adsorbents (24 mg, $34.5 \mathrm{mg}$, and $33 \mathrm{mg}$ combined masses) were found to be $0.264,0.356$, and 0.801 (which were all 


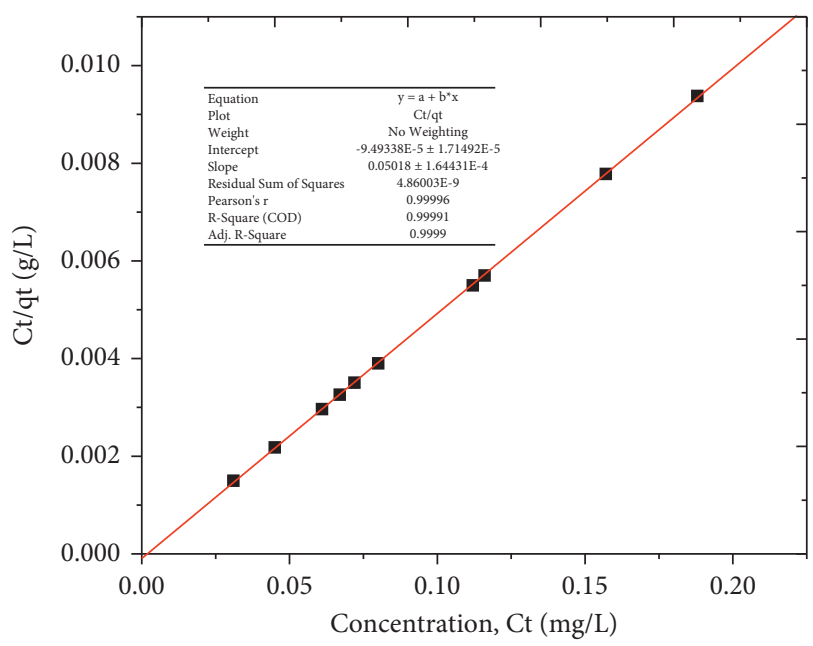

(a)

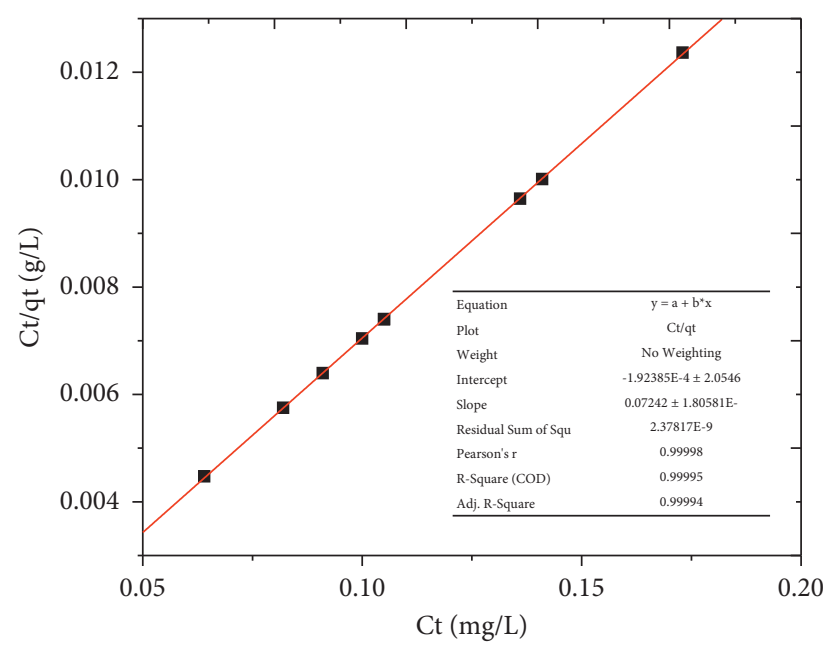

(b)

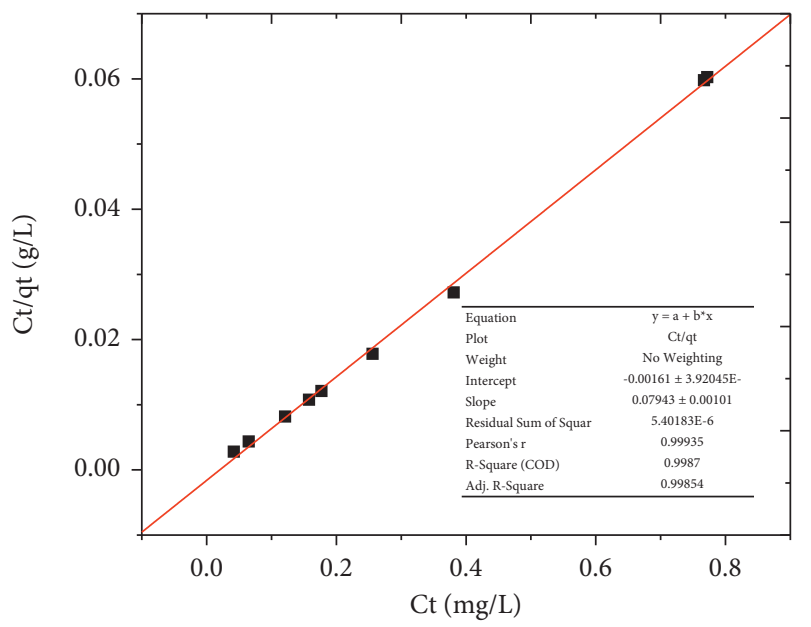

(c)

Figure 7: Langmuir isotherm model fit for (a) $24 \mathrm{mg}$, (b) $34.5 \mathrm{mg}$, and (c) $33 \mathrm{mg}$ combined mass HAP-BENT adsorbents.

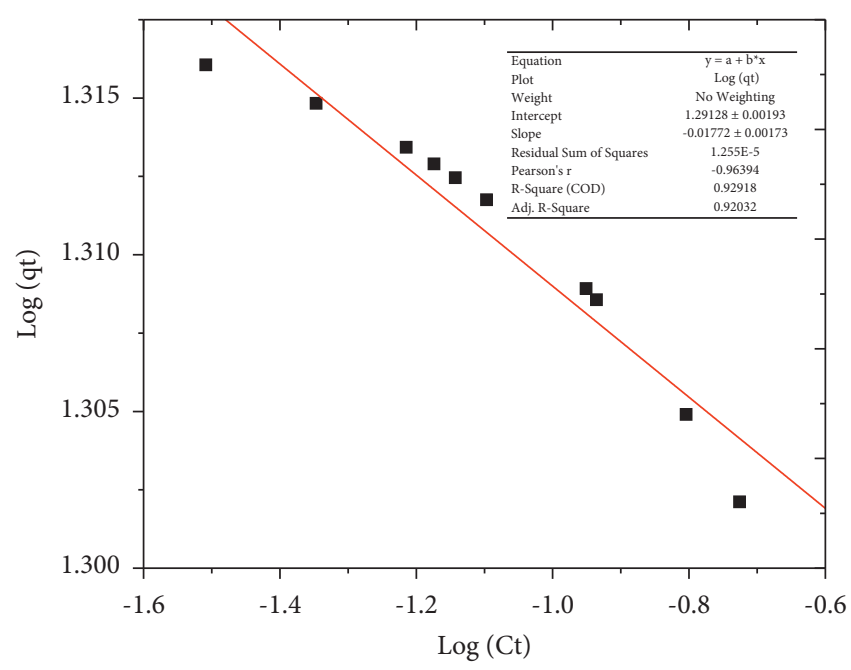

(a)

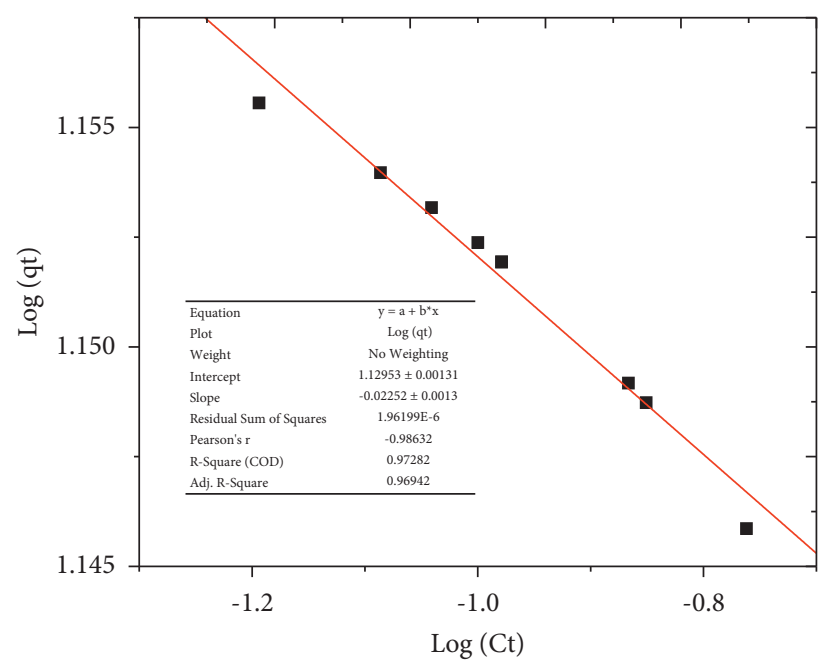

(b)

Figure 8: Continued. 


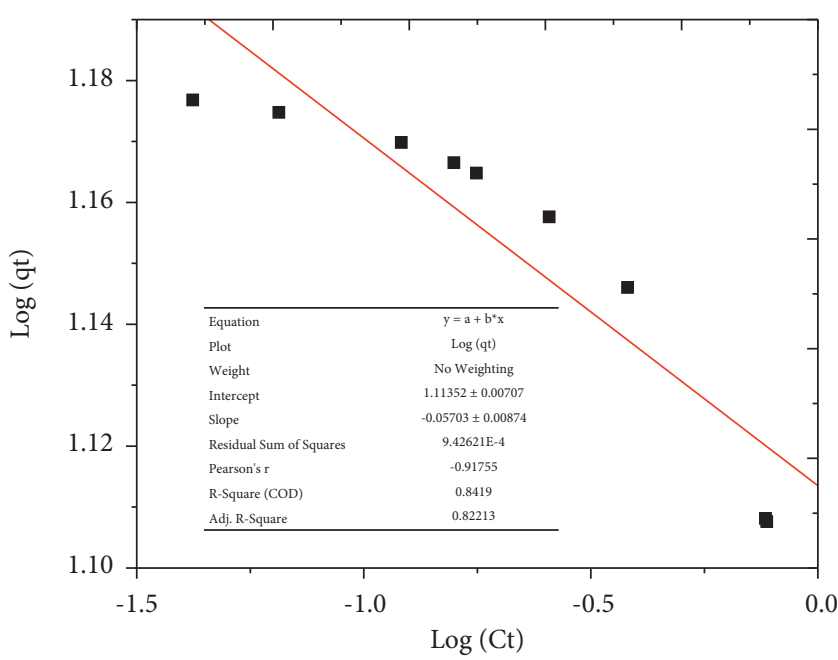

(c)

FIGURE 8: Freundlich isotherm model fit for (a) $24 \mathrm{mg}$, (b) $34.5 \mathrm{mg}$, and (c) $33 \mathrm{mg}$ combined mass HAP-BENT adsorbents.

TABLE 3: Isotherm model parameters for HAP-BENT best adsorbents.

\begin{tabular}{|c|c|c|c|c|c|c|}
\hline \multirow{2}{*}{ Adsorbent mass (mg) } & \multicolumn{3}{|c|}{ Langmuir model } & \multicolumn{3}{|c|}{ Freundlich model } \\
\hline & $K_{L}(\mathrm{~L} / \mathrm{mg})$ & $q_{\max }(\mathrm{mg} / \mathrm{L})$ & $R$-Square & $K_{F}(\mathrm{mg} / \mathrm{g})$ & $n$ & $R$-Square \\
\hline 24.0 & 557.77 & 19.92 & 0.99 & 19.55 & 56.5 & 0.93 \\
\hline 34.5 & 362.00 & 13.81 & 1.00 & 13.47 & 44.4 & 0.97 \\
\hline 33.0 & 49.62 & 12.59 & 1.00 & 12.92 & 17.86 & 0.84 \\
\hline
\end{tabular}

TABLE 4: Kinetic model parameters for adsorption of MB.

\begin{tabular}{|c|c|c|c|c|c|c|c|}
\hline \multirow{2}{*}{ Adsorbent HAP: BENT mass (mg) } & \multirow{2}{*}{ Experiment $q_{\mathrm{e}}(\mathrm{mg} / \mathrm{g})$} & \multicolumn{3}{|c|}{ Pseudo-first-order (PFO) } & \multicolumn{3}{|c|}{ Pseudo-second-order (PSO) } \\
\hline & & $K_{1}\left(\min ^{-1}\right)$ & $q_{e}(\mathrm{mg} / \mathrm{g})$ & $R^{2}$ & $K_{2}(\mathrm{~g} / \mathrm{mg} / \mathrm{min})$ & $q_{e}(\mathrm{mg} / \mathrm{g})$ & $R^{2}$ \\
\hline 24.0 & 20.70 & 0.049 & 12.189 & 0.48 & 0.002 & 20.75 & 1 \\
\hline 34.5 & 14.23 & 0.007 & 0.001 & 0.33 & 0.005 & 14.25 & 1 \\
\hline 33.0 & 12.81 & 0.051 & 952.581 & 0.63 & 0.006 & 12.59 & 0.99 \\
\hline
\end{tabular}

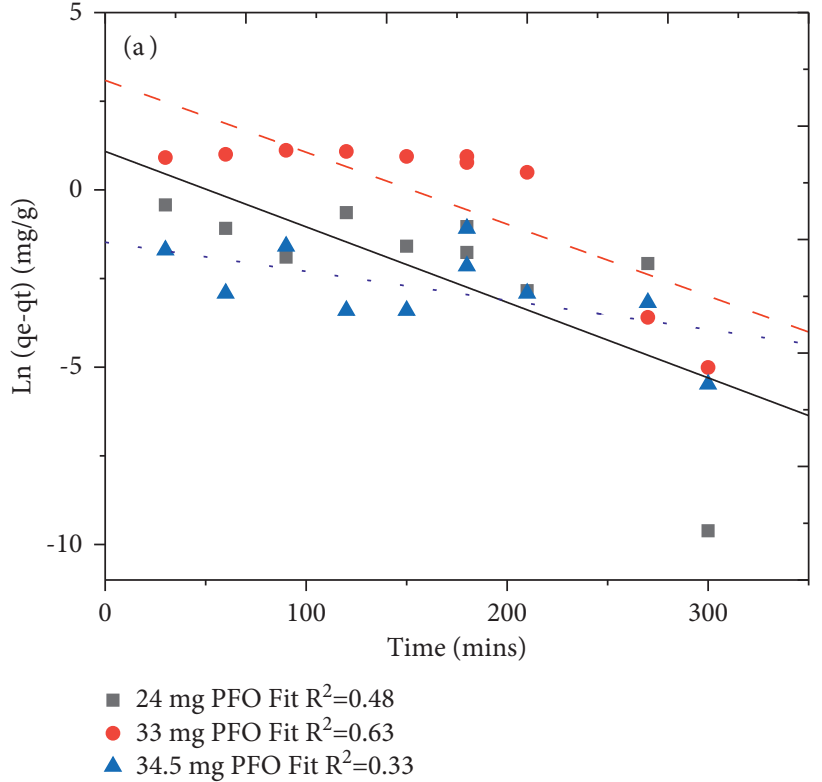

(a)

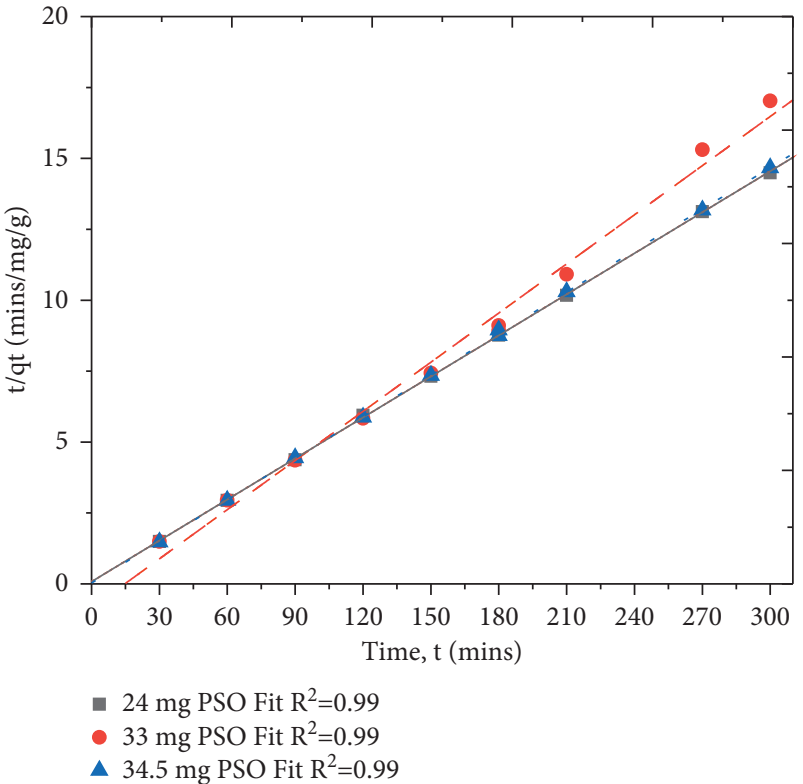

(b)

FIgURE 9: Kinetic modeling. (a) PFO model fit. (b) PSO modeling fit for HAP:BENT adsorbent combined masses of $24 \mathrm{mg}$, $33 \mathrm{mg}$, and $34.5 \mathrm{mg}$. 


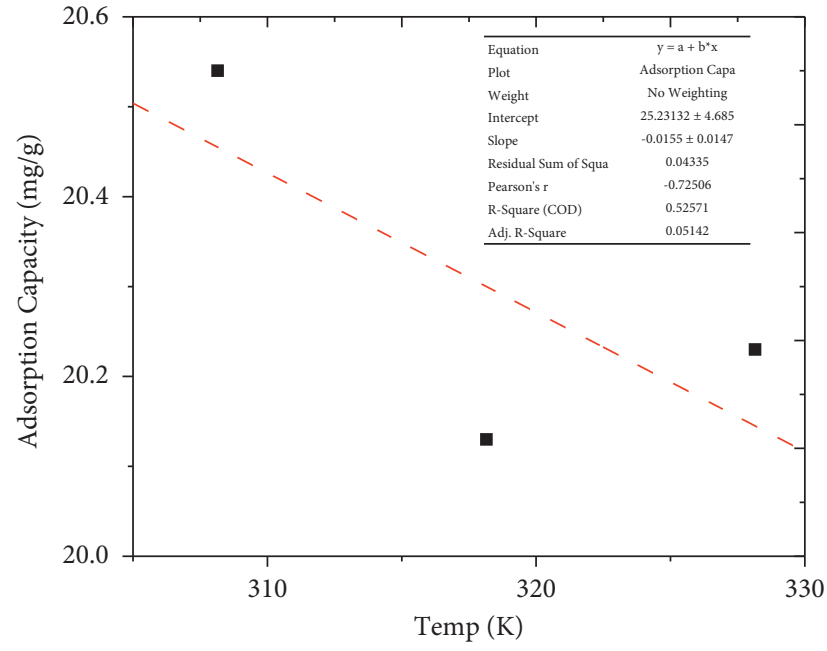

(a)

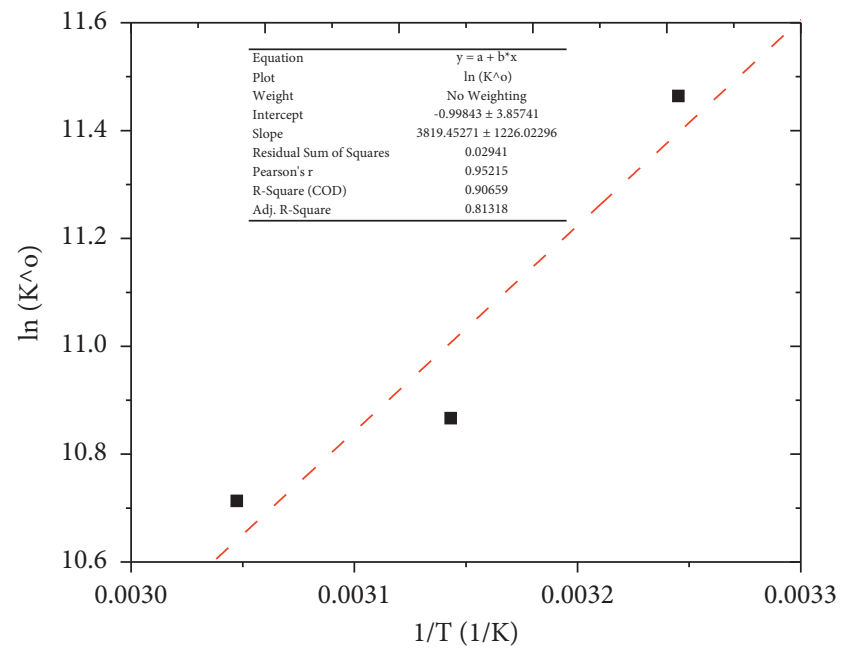

(b)

Figure 10: HAP:BENT adsorbent $(24 \mathrm{mg}$ ) adsorption data analysis at $60 \mathrm{~min}$ of contact time and $\mathrm{pH}=5.8 \mathrm{regarding}$ (a) the influence of temperature and (b) Van't Hoff plot for thermodynamical studies.

between 0 and 1). According to Tchomgui-Kamga et al. [40], the adsorption nature can be described using the separation factor and that it can be indicated to be either linear $\left(R_{L}=1\right)$, irreversible $\left(R_{L}=0\right)$, unfavorable $\left(R_{L}>1\right)$, or favorable $\left(0<R_{L}<1\right)$ [44]. The values from this current research support the conclusion that the adsorption favors the Langmuir isotherm model and is supported by other researchers $[45,46]$.

The kinetics of the adsorption process which is critical to process efficiency was also investigated and the understanding of mechanism(s) was involved. This was done by fitting adsorption data to equations (5) and (6) for PFO and PSO, respectively. The PFO and PSO key parameters for best adsorbent masses of $24.0 \mathrm{mg}, 33.0 \mathrm{mg}$, and $34.5 \mathrm{mg}$ are presented in Table 4 . The R-square values from fitting as indicated in Table 4 and Figure 9 show that the kinetic process is best described by PSO. In addition, the adsorption capacity values for the PSO in all cases can be found to be comparable to the experimental value to the PFO adsorption capacity values. This research output with regard to the kinetics being best described with PSO was supported by other studies [45-48].

\subsection{Effect of Temperature and Thermodynamical Modeling.} The effect of temperature studies for HAP:BENT composites on $\mathrm{MB}$ adsorption was explored on the best adsorbent mass, $24.00 \mathrm{mg}$ HAP:BENT composite only. The temperatures at which the adsorption was undertaken were $308.15 \mathrm{~K}$, $318.15 \mathrm{~K}$, and $328.15 \mathrm{~K}$. The adsorption capacities of the HAP: BENT (24 mg mass) for MB decrease slightly with an increase in temperature (Figure 10(a)). The decrease of adsorption capacity with increasing temperature indicates that the adsorption is an exothermic process [48]. The increasing temperature may decrease the adsorptive forces between the dye species and the active sites on the adsorbent surface as a result of decreasing adsorption capacity [49].
The enthalpy $\left(\Delta H^{\circ}\right)$ and entropy $\left(\Delta S^{\circ}\right)$ parameters were estimated from the classical equations (8) and (9). The plot of $\operatorname{Ln} K_{L}^{\circ}$ versus $1 / T$ from equation (8) yielded a straight line (Figure 10(b)), and the values of $\Delta H^{\circ}(\mathrm{kJ} / \mathrm{mol})$ and $\Delta S^{\circ}(\mathrm{J} / \mathrm{mol}$ $\mathrm{K})$ were calculated from the intercept and slope of the plots, respectively. The values of $\Delta G^{\circ}(\mathrm{kJ} / \mathrm{mol})$ were calculated from $\Delta H^{\circ}$ and $\Delta S^{\circ}$ (Table 5) using equation (9). The Van't Hoff (equation (9)) plot indicates an exothermic adsorption process. The negative $\Delta G^{\circ}$ values confirmed the feasibility and spontaneity of the adsorption process.

3.6. Proposed Mechanism of MB Removal. The adsorption mechanism channels are known to depend on the compositions of the composite and their subsequent availability of suitable sites. HAP adsorption potency for MB as well as clay minerals has been documented to be dependent on $\mathrm{pH}$. Regarding MB adsorption on HAP, lower adsorption has been reported at lower $\mathrm{pH}$ compared to adsorption between high values $\mathrm{pH}$ of $8-12$. The most identified mechanisms involve hydrogen bonding, electrostatic attraction, and acid interaction.

Clays are hydrous aluminum phyllosilicate generally made up of an octahedral arrangement of silicate sheets sandwiched between two tetrahedral aluminas with various cations. Hydroxyl groups located on the lateral cleavages of clay crystallites are capable of protonation-deprotonation reactions depending on the $\mathrm{pH}$ of the surrounding solution [41]. The presence of the 'hidden' $\mathrm{OH}$ and water molecules is confirmed by the FTIR plots presented in Figure 3(b). The broken bonds and $\mathrm{M}$ (cations)-OH bonds along the surfaces of the clay crystals result in hydrolysis [27].

Figure 11 is a schematic representation of the adsorption of MB by the HAP-clay composite. This was drawn after considering the mechanism of MB adsorption by HAP and clay separately via literature by Vezentsev et al. [50] and others $[45-47,50]$. The composite adsorbent within the basic media protons dissociates resulting in HAP-clay negative 
TABLE 5: Thermodynamical parameters for MB adsorption onto HAP:BENT (24 mg) adsorbent.

\begin{tabular}{lcccccc}
\hline Temperature, $T(\mathrm{~K})$ & $K_{L}(\mathrm{~L} / \mathrm{mg})$ & $K_{L}{ }^{\mathrm{o}}($ dimensionless $)$ & $\operatorname{Ln} K_{L}^{\mathrm{o}}$ & $\Delta G^{\mathrm{o}}(\mathrm{kJ} / \mathrm{mol})$ & $\Delta H^{\mathrm{o}}(\mathrm{kJ} / \mathrm{mol})$ & $\Delta S^{\mathrm{o}}(\mathrm{J} / \mathrm{K} / \mathrm{mol})$ \\
\hline 308.15 & 297.80 & 95240.36 & 11.46 & -29.37 & -31.76 & 8.30 \\
318.15 & 163.84 & 52405.53 & 10.87 & -28.74 & - & - \\
328.15 & 140.51 & 44941.89 & 10.71 & -29.23 & - \\
\hline
\end{tabular}

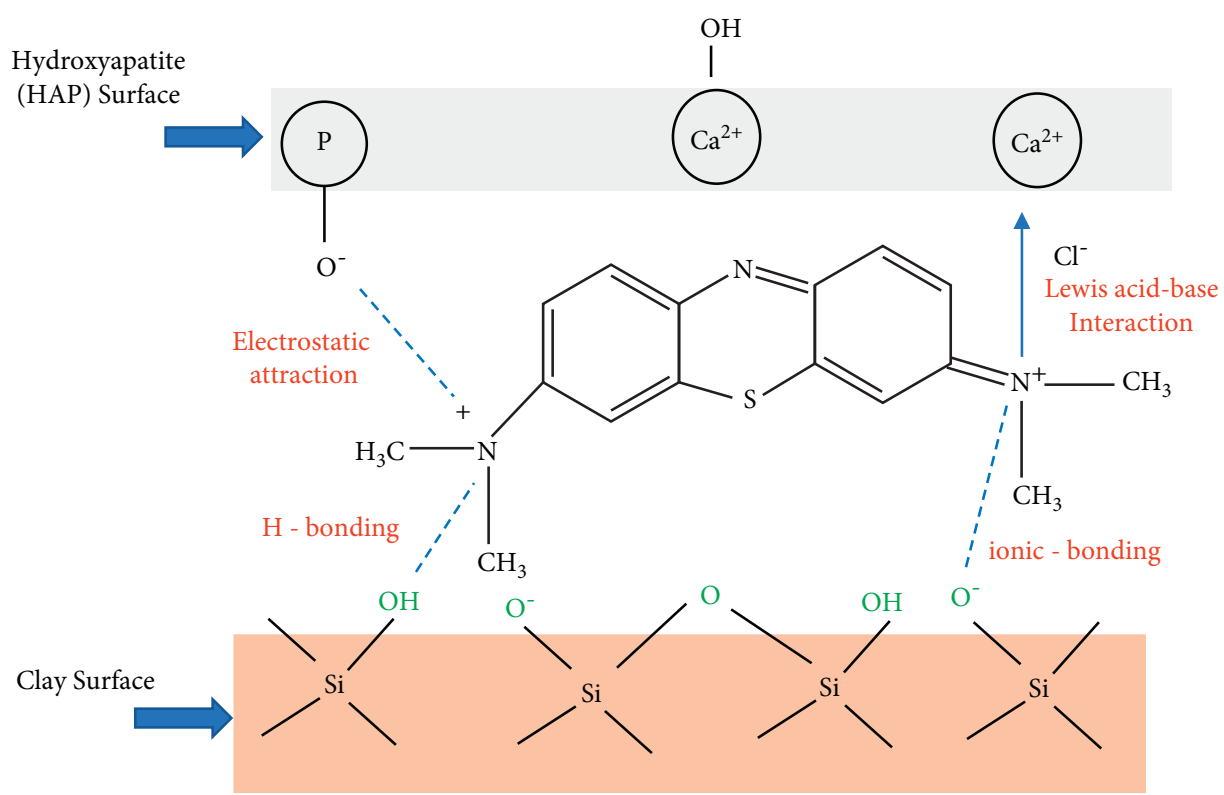

FIGURE 11: Schematic representation of proposed MB adsorption mechanism on HAP:clay composite.

charge which promotes adsorption of $\mathrm{MB}$ cations. As a result, the positively charged surface cannot absorb MB cations effectively because of electrostatic repulsion [50]. Despite low $\mathrm{pH}$, electrostatic repulsion, and competitive adsorption of $\mathrm{H}^{+}$ ions, a reasonable amount of $\mathrm{MB}$ is absorbed. The high removal efficiency also associated with HAP:BENT is mainly due to the presence of the bentonite which is smectite clay (three-layer type) as compared to kaolin and halloysite which are two layers. Bentonites are noted for a high degree of chemical substitution within their smectite structure, the nature of the exchangeable cations present, and the type and amount of impurities present $[51,52]$.

\section{Conclusion}

HAP was successfully synthesized from chicken eggshells and characterized. The FTIR characterization compares well with scholarly literature. This was confirmed via XRD analysis. The adsorption capacity of the class of HAP-BENT adsorbents was found to have higher values, followed by HAP-HNT and then HAP-KAO adsorbents. Similar trends were observed for the removal efficiency parameter for the composites. The combined mass of $24 \mathrm{mg}$ of HAP-BENT resulted in $20.2 \mathrm{mg} / \mathrm{g}$ and was the highest in all composite adsorptions. The combined masses of $24 \mathrm{mg}, 23 \mathrm{mg}$, and $22 \mathrm{mg}$ (representing 20,15, and 10 percentages of HAP mass used as a mass of bentonite) had adsorption capacity values of $20.7 \mathrm{mg} / \mathrm{g}, 17.2 \mathrm{mg} / \mathrm{g}$, and $17.9 \mathrm{mg} / \mathrm{g}$, respectively. The
HAP-BENT adsorbents with combined masses of $24 \mathrm{mg}$, $34.5 \mathrm{mg}$, and $33 \mathrm{mg}$ were found to show the best performances in terms of removal efficiency and adsorptive capacity. Generally, for all adsorbents HAP-BENT, removal efficiency values increased with increasing contact time with marginal increases from the third hour of contact time. The adsorption capacity values were found to decrease as the adsorbent dosage increases. The adsorption process for the HAP-BENT can be described with the Langmuir isotherm adsorption model and PSO kinetic modeling. Regarding the thermodynamical modeling, the negative values of the enthalpy change and Gibbs free energy indicate the exothermic and spontaneous process. This research confirms the use of natural materials for water treatment and the ease of use.

\section{Data Availability}

The "Data supporting work" file used to support the findings of this study is included within the supplementary information file.

\section{Conflicts of Interest}

There are no conflicts of interest.

\section{Acknowledgments}

This project was partly funded by Cambridge-Africa Partnership for Research Excellence (CAPREx) project and the 
ALBORADA research fund at the University of Ghana, Legon, Ghana. Dr. Ebenezer Annan acknowledges Miss Beatrice Agyapomah of the Physics Department, University of Ghana, for her assistance in XRD analysis.

\section{Supplementary Materials}

SI 1-Adsorbent: HAP-HNT, SI 2-Adsorbent: HAP-KAOLIN, SI 3-Adsorbent: HAP-BENTONITE, SI 4-Kinetic models Data, and SI 5-Isotherm models data. (Supplementary Materials)

\section{References}

[1] O. Hamdaoui, F. Saoudi, M. Chiha, and E. Naffrechoux, "Sorption of malachite green by a novel sorbent, dead leaves of plane tree: equilibrium and kinetic modeling," Chemical Engineering Journal, vol. 143, no. 1-3, pp. 73-84, 2008.

[2] N. Kannan and M. M. Sundaram, "Kinetics and mechanism of removal of methylene blue by adsorption on various carbonsa comparative study," Dyes and Pigments, vol. 51, no. 1, pp. 25-40, 2001.

[3] J. P. Essien, E. D. Inam, D. I. Ikpe, G. E. Udofia, and N. U. Benson, "Ecotoxicological status and risk assessment of heavy metals in municipal solid wastes dumpsite impacted soil in Nigeria," Environmental Nanotechnology, Monitoring \& Management, vol. 11, Article ID 100215, 2019.

[4] R. Srivastava and I. R. Sofi, "Impact of synthetic dyes on human health and environment," in Impact of Textile Dyes on Public Health and the Environment, pp. 146-161, IGI Global, PA, USA, 2020.

[5] T. Robinson, G. McMullan, R. Marchant, and P. Nigam, "Remediation of dyes in textile effluent: a critical review on current treatment technologies with a proposed alternative," Bioresource Technology, vol. 77, no. 3, pp. 247-255, 2001.

[6] K.-T. Chung, "Azo dyes and human health: a review," Journal of Environmental Science and Health, Part C, vol. 34, no. 4, pp. 233-261, 2016.

[7] G. J. Nohynek, R. Fautz, F. Benech-Kieffer, and H. Toutain, "Toxicity and human health risk of hair dyes," Food and Chemical Toxicology, vol. 42, no. 4, pp. 517-543, 2004.

[8] G. Chen, J. Pan, B. Han, and H. Yan, "Adsorption of methylene blue on montmorillonite," Journal of Dispersion Science and Technology, vol. 20, no. 4, pp. 1179-1187, 1999.

[9] V. Vimonses, S. Lei, B. Jin, C. W. Chow, and C. Saint, "Kinetic study and equilibrium isotherm analysis of Congo Red adsorption by clay materials," Chemical Engineering Journal, vol. 148, no. 2-3, pp. 354-364, 2009.

[10] A. Bhatnagar and M. Sillanpää, "Utilization of agro-industrial and municipal waste materials as potential adsorbents for water treatment-a review," Chemical Engineering Journal, vol. 157, no. 2-3, pp. 277-296, 2010.

[11] S. Nethaji, A. Sivasamy, and A. B. Mandal, "Adsorption isotherms, kinetics and mechanism for the adsorption of cationic and anionic dyes onto carbonaceous particles prepared from Juglans regia shell biomass," International journal of Environmental Science and Technology, vol. 10, no. 2, pp. 231-242, 2013.

[12] A. Gürses, S. Karaca, Ç. Doğar, R. Bayrak, M. Açıkyıldız, and M. Yalçın, "Determination of adsorptive properties of clay/ water system: methylene blue sorption," Journal of Colloid and Interface Science, vol. 269, no. 2, pp. 310-314, 2004.
[13] R. A. Shawabkeh and M. F. Tutunji, "Experimental study and modeling of basic dye sorption by diatomaceous clay," Applied Clay Science, vol. 24, no. 1-2, pp. 111-120, 2003.

[14] D. Ghosh and K. G. Bhattacharyya, "Adsorption of methylene blue on kaolinite," Applied Clay Science, vol. 20, no. 6, pp. 295-300, 2002.

[15] M. Bagane and S. Guiza, "Elimination d'un colorant des effluents de l'industrie textile par adsorption," Annales de Chimie Science des MatÃriaux, vol. 25, no. 8, pp. 615-625, 2000.

[16] C. A. P. Almeida, N. A. Debacher, A. J. Downs, L. Cottet, and C. A. D. Mello, "Removal of methylene blue from colored effluents by adsorption on montmorillonite clay," Journal of Colloid and Interface Science, vol. 332, no. 1, pp. 46-53, 2009.

[17] I. Smičiklas, S. Dimović, I. Plećaš, and M. Mitrić, "Removal of $\mathrm{Co}^{2+}$ from aqueous solutions by hydroxyapatite," Water Research, vol. 40, no. 12, pp. 2267-2274, 2006.

[18] D. T. Le, T. P. T. Le, H. T. Do et al., "Fabrication of porous hydroxyapatite granules as an effective adsorbent for the removal of aqueous $\mathrm{Pb}$ (II) ions," Journal of Chemistry, vol. 2019, Article ID 8620181, 2019.

[19] Z. A. Al-Ahmed, N. S. Al-Radadi, M. K. Ahmed, K. Shoueir, and M. El-Kemary, "Dye removal, antibacterial properties, and morphological behavior of hydroxyapatite doped with Pd ions," Arabian Journal of Chemistry, vol. 13, no. 12, pp. 8626-8637, 2020.

[20] K. Allam, A. El Bouari, B. Belhorma, and L. Bih, "Removal of methylene blue from water using hydroxyapatite submitted to microwave irradiation," Journal of Water Resource and Protection, vol. 8, no. 3, pp. 358-371, 2016.

[21] E. Broda and E. Skwarek, "Clay, hydroxyapatite and their composites-brief review," Nanooptics and Photonics, Nanochemistry and Nanbiotechnology and Their Applications, Springer, Berlin, Germany, pp. 255-272, 2020.

[22] R. Bazargan-Lari, M. Bahrololoom, and A. Nemati, "Sorption behavior of $\mathrm{Zn}$ (II) ions by low cost and biological natural hydroxyapatite/chitosan composite from industrial waste water," Journal of Food Agriculture and Environment, vol. 9, no. 3/4, pp. 892-897, 2011.

[23] G. N. Kousalya, M. Rajiv Gandhi, C. Sairam Sundaram, and S. Meenakshi, "Synthesis of nano-hydroxyapatite chitin/chitosan hybrid biocomposites for the removal of $\mathrm{Fe}(\mathrm{III})$," Carbohydrate Polymers, vol. 82, no. 3, pp. 594-599, 2010.

[24] H. Hou, R. Zhou, P. Wu, and L. Wu, "Removal of Congo red dye from aqueous solution with hydroxyapatite/chitosan composite," Chemical Engineering Journal, vol. 211-212, pp. 336-342, 2012.

[25] M. Ersan, U. A. Guler, U. Acıkel, and M. Sarioglu, "Synthesis of hydroxyapatite/clay and hydroxyapatite/pumice composites for tetracycline removal from aqueous solutions," Process Safety and Environmental Protection, vol. 96, pp. 22-32, 2015.

[26] P. RoyChoudhury, S. Majumdar, S. Sarkar, B. Kundu, and G. C. Sahoo, "Performance investigation of $\mathrm{Pb}(\mathrm{II})$ removal by synthesized hydroxyapatite based ceramic ultrafiltration membrane: bench scale study," Chemical Engineering Journal, vol. 355, pp. 510-519, 2019.

[27] H. Freundlich, "Over the adsorption in solution," Journal of Physical Chemistry, vol. 57, no. 385471, pp. 1100-1107, 1906.

[28] Y. Li, Q. Li, C. Wu, X. Luo, X. Yu, and M. Chen, "The inappropriate application of the regression Langmuir Qm for adsorption capacity comparison," The Science of the Total Environment, vol. 699, Article ID 134222, 2020.

[29] J. Lin and L. Wang, "Comparison between linear and nonlinear forms of pseudo-first-order and pseudo-second-order 
adsorption kinetic models for the removal of methylene blue by activated carbon," Frontiers of Environmental Science and Engineering in China, vol. 3, no. 3, pp. 320-324, 2009.

[30] Z. Ren, B. Jia, G. Zhang et al., "Study on adsorption of ammonia nitrogen by iron-loaded activated carbon from low temperature wastewater," Chemosphere, vol. 262, Article ID 127895, 2020.

[31] L. Pontoni and M. Fabbricino, "Use of chitosan and chitosanderivatives to remove arsenic from aqueous solutions-a mini review," Carbohydrate Research, vol. 356, pp. 86-92, 2012.

[32] S. Salvestrini, V. Leone, P. Iovino, S. Canzano, and S. Capasso, "Considerations about the correct evaluation of sorption thermodynamic parameters from equilibrium isotherms," The Journal of Chemical Thermodynamics, vol. 68, pp. 310-316, 2014.

[33] C.-C. Wu, S.-T. Huang, T.-W. Tseng, Q.-L. Rao, and H.-C. Lin, "FT-IR and XRD investigations on sintered fluoridated hydroxyapatite composites," Journal of Molecular Structure, vol. 979, no. 1-3, pp. 72-76, 2010.

[34] G. Gergely, F. Wéber, I. Lukács et al., "Preparation and characterization of hydroxyapatite from eggshell," Ceramics International, vol. 36, no. 2, pp. 803-806, 2010.

[35] P. Pasbakhsh, H. Ismail, M. N. A. Fauzi, and A. A. Bakar, "EPDM/modified halloysite nanocomposites," Applied Clay Science, vol. 48, no. 3, pp. 405-413, 2010.

[36] L. M. Rodríguez-Lorenzo, J. N. Hart, and K. A. Gross, "Structural and chemical analysis of well-crystallized hydroxyfluorapatites," The Journal of Physical Chemistry B, vol. 107 , no. 33, pp. 8316-8320, 2003.

[37] W. Weber and J. Morris, "Intraparticle diffusion during the sorption of surfactants onto activated carbon," Journal of the Sanitary Engineering Division-American Society of Civil Engineers, vol. 89, no. 1, pp. 53-61, 1963.

[38] A. Maiti, J. K. Basu, and S. De, "Chemical treated laterite as promising fluoride adsorbent for aqueous system and kinetic modeling," Desalination, vol. 265, no. 1-3, pp. 28-36, 2011.

[39] A. Goswami and M. K. Purkait, "Kinetic and equilibrium study for the fluoride adsorption using pyrophyllite," Separation Science and Technology, vol. 46, no. 11, pp. 1797-1807, 2011.

[40] E. Tchomgui-Kamga, V. Alonzo, C. P. Nanseu-Njiki, N. Audebrand, E. Ngameni, and A. Darchen, "Preparation and characterization of charcoals that contain dispersed aluminum oxide as adsorbents for removal of fluoride from drinking water," Carbon, vol. 48, no. 2, pp. 333-343, 2010.

[41] M. A. Al-Ghouti, M. A. M. Khraisheh, S. J. Allen, and M. N. Ahmad, "The removal of dyes from textile wastewater: a study of the physical characteristics and adsorption mechanisms of diatomaceous earth," Journal of Environmental Management, vol. 69, no. 3, pp. 229-238, 2003.

[42] G. Ciobanu, M. Harja, M. Diaconu, C. Cimpeanu, R. Teodorescu, and D. Bucur, "Crystal violet dye removal from aqueous solution by nanohydroxyapatite," Journal of Food Agriculture and Environment, vol. 12, no. 1, pp. 499-502, 2014.

[43] K. S. Low, C. K. Lee, and L. L. Heng, "Sorption of basic dyes by Hydrilla verticillata," Environmental Technology, vol. 15, no. 2, pp. 115-124, 1994.

[44] T. W. Weber and R. K. Chakravorti, "Pore and solid diffusion models for fixed-bed adsorbers," AIChE Journal, vol. 20, no. 2, pp. 228-238, 1974.

[45] K. Mukherjee, A. Kedia, K. Jagajjanani Rao, S. Dhir, and S. Paria, "Adsorption enhancement of methylene blue dye at kaolinite clay-water interface influenced by electrolyte solutions," RSC Advances, vol. 5, no. 39, pp. 30654-30659, 2015.
[46] Y. Bentahar, K. Draoui, C. Hurel, O. Ajouyed, S. Khairoun, and N. Marmier, "Physico-chemical characterization and valorization of swelling and non-swelling Moroccan clays in basic dye removal from aqueous solutions," Journal of African Earth Sciences, vol. 154, pp. 80-88, 2019.

[47] A. H. Jawad and A. S. Abdulhameed, "Mesoporous Iraqi red kaolin clay as an efficient adsorbent for methylene blue dye: adsorption kinetic, isotherm and mechanism study," Surfaces and Interfaces, vol. 18, Article ID 100422, 2020.

[48] B. Nandi, A. Goswami, and M. Purkait, "Removal of cationic dyes from aqueous solutions by kaolin: kinetic and equilibrium studies," Applied Clay Science, vol. 42, no. 3-4, pp. 583-590, 2009.

[49] A. Ofomaja and Y. Ho, "Equilibrium sorption of anionic dye from aqueous solution by palm kernel fibre as sorbent," Dyes and Pigments, vol. 74, no. 1, pp. 60-66, 2006.

[50] A. I. Vezentsev, D. M. Thuy, L. F. Goldovskaya-Peristaya, and N. A. Glukhareva, "Adsorption of methylene blue on the composite sorbent based on bentonite-like clay and hydroxyapatite," Indonesian Journal of Chemistry, vol. 18, no. 4, pp. 733-741, 2018.

[51] O. Ombaka, "Characterization and classification of clay minerals for potential applications in Rugi Ward, Kenya," African Journal of Environmental Science and Technology, vol. 10, no. 11, pp. 415-431, 2016.

[52] C. Tournassat, I. C. Bourg, C. I. Steefel, and F. Bergaya, "Surface properties of clay minerals," Developments in Clay Science, vol. 6, pp. 5-31, 2015. 